\title{
An Efficient Analysis Methodology for Fluted-Core Composite Structures
}

\author{
Leonard Oremont ${ }^{1}$ \\ Lockheed Martin Corporation, Hampton, VA 23681-2199, USA \\ and \\ Marc R. Schultz ${ }^{2}$ \\ NASA Langley Research Center, Hampton, VA 23681-2199, USA
}

\begin{abstract}
The primary loading condition in launch-vehicle barrel sections is axial compression, and it is therefore important to understand the compression behavior of any structures, structural concepts, and materials considered in launch-vehicle designs. This understanding will necessarily come from a combination of test and analysis. However, certain potentially beneficial structures and structural concepts do not lend themselves to commonly used simplified analysis methods, and therefore innovative analysis methodologies must be developed if these structures and structural concepts are to be considered. This paper discusses such an analysis technique for the fluted-core sandwich composite structural concept. The presented technique is based on commercially available finite-element codes, and uses shell elements to capture behavior that would normally require solid elements to capture the detailed mechanical response of the structure. The shell thicknesses and offsets using this analysis technique are parameterized, and the parameters are adjusted through a heuristic procedure until this model matches the mechanical behavior of a more detailed shell-and-solid model. Additionally, the detailed shell-and-solid model can be strategically placed in a larger, global shell-only model to capture important local behavior. Comparisons between shell-only models, experiments, and more detailed shell-and-solid models show excellent agreement. The discussed analysis methodology, though only discussed in the context of fluted-core composites, is widely applicable to other concepts.
\end{abstract}

\section{Introduction}

$\mathrm{T}$ he primary loading condition in launch-vehicle barrel sections is axial compression, and it is therefore important to understand the compression behavior of any structures, structural concepts, and materials considered in launch-vehicle designs. This understanding will necessarily come from a combination of test and analysis. However, certain potentially beneficial structures and structural concepts do not lend themselves to commonly used simplified analysis methods, and therefore innovative analysis methodologies must be developed if these structures and structural concepts are to be considered. This paper discusses such an analysis technique for the fluted-core sandwich composite structural concept. This analysis methodology, though only discussed in the context of flutedcore composites, is widely applicable to other concepts including other composite designs such as those with corrugated webs or I-beam stiffeners, and integrally stiffened metallic structures that include complexities such as fillets or other form of variable thickness in the interface between skins and stiffeners like those often found on isogrid and orthogrid structures.

Fiber-reinforced composite structures are increasingly considered in efforts to develop new launch vehicles because of potential benefits over traditional metallic structures. Such benefits can include lower mass, better fatigue resistance, and reduced costs. Structures recently baselined specifically as composite during NASA's recent launchvehicle-development efforts included dry-shell components such as interstages, shrouds, and frustums. ${ }^{1-4}$ The

\footnotetext{
${ }^{1}$ Structural Engineer, NASA Langley Research Center, Mail Stop 460, AIAA Senior Member.

${ }^{2}$ Research Aerospace Engineer, Structural Mechanics and Concepts Branch, 8 West Taylor St., Mail Stop 190, AIAA Senior Member.
} 
structural efficiency of sandwich composite shells in terms of high bending stiffness and low density is well known. Traditional sandwich composites (e.g., those made with a honeycomb or foam core and laminated composite faces), however, can have poor damage resistance and damage tolerance, and it can be difficult to measure manufacturing defects and damage. To potentially overcome some of these shortcomings, other sandwich-composite concepts are being developed and considered for launch-vehicle applications. The fluted-core composite concept is one such sandwich concept, and is considered herein. Fluted-core composites are sandwich composites that consist of integral angled web members and structural radius fillers spaced between laminate face sheets, as shown in Fig. 1. A discussion of perceived benefits and drawbacks for honeycomb-core and fluted-core composites was presented recently. ${ }^{5}$

It is often reasonable to model a sandwich structure as a shell. Additionally, it is often reasonable to model a stiffened structure as a shell with discrete beams for the stiffeners, ${ }^{6}$ or if the stiffeners are closely and equally spaced to have their properties, including stiffener eccentricity, averaged or smeared over the surface of the shell. ${ }^{7}$ These types of approaches have recently been applied to compression-loaded isogrid structures in assessments prior to testing ${ }^{8}$ and to fluted-core structures for initial-design-type analyses. ${ }^{9}$ However, the compression response of flutedcore components has a number of complexities that can make either smeared-shell or shell-beam models, as well as linear analyses, insufficient for predicting their behavior. In particular, local buckling can occur in the facesheets and webs before any material failures or global-buckling events. Though not catastrophic by themselves, these local buckling responses must be captured in analyses because they may lead to other failures in the postbuckling load range. Smeared-shell analyses are not capable of capturing these local-buckling responses. Nonlinear analyses that capture enough of the cross-sectional detail are needed to predict the failures that occur in the postbuckling range. Care is required in developing finite-element models that can accurately capture this complex behavior. Earlier efforts to address these difficulties resorted to detailed finite element meshes that included both facesheets and webs as shell elements, ${ }^{10-12}$ or a combination of solid and shell elements when necessary because of the presence of filled

(or filleted) face-web joints. ${ }^{5,13}$ However, the use of solid elements can produce models with a large numbers of degrees of freedom that can make the analysis of complex built-up structures impossible with available computer resources. Because of the variety of designs and manufacturing considerations envisioned for fluted-core structures and their relative novelty, there is limited structural data associated with them, and they may therefore require a lengthy development and certification process. The analysis methodology presented herein could potentially shorten the time and lower the costs involved in this development by providing greater understanding, better predictions, and therefore greater confidence on the effects of design changes. The developed methodology is based on commercially available finite-element codes and uses shell elements to capture behavior that would normally require solid elements; in this methodology, the shell thickness and offset properties of these additional shell elements are parameterized. A combination shell-and-solid model is developed as part of the discussed methodology and is used as the standard with which to iteratively tune the shell-element parameters so that the structural response of the shell-only model is essentially equivalent to that of the shell-and-solid model. This approach is different in that geometry of certain small sections of the physical structure being modeled is considered less important than the structural response, and to the knowledge of the authors, this type of approach has not been used before. Additionally, the more detailed shell-and-solid model can be strategically placed in a larger shell-only model to capture important local behavior or be used as a local model for which the loads and boundary conditions are inferred from the shell-only global model.

A description of the test articles that are considered in the current study is given in Section II. Two methodologies used to produce finite element models for both small and large fluted-core articles are discussed in Section III. One of these methodologies uses solid elements to model the noodle region, and the other methodology is the primary subject of this paper and uses shell elements to efficiently model the noodle region. Experimental test results from Ref. 5 are also discussed and compared with results from the two methodologies in Section III. Concluding remarks are given in Section IV.

\section{Test-Article Description}

Though the analysis methodology developed in this paper is intended to help improve the understanding of the behavior of future fluted-core composite structures and test articles, it is also necessary to use previous experiments and detailed analyses to validate the methodology. As such, there are three test-article configurations discussed herein; experimental results from one of these configurations will be used for analysis-method validation, and the analysis methodology developed herein will be used to make pre-test predictions for the other two test-article configurations. All the test articles were fabricated by The Boeing Company by wrapping unidirectional $350-^{\circ} \mathrm{F}$-cure toughened carbon-epoxy prepreg plies around trapezoidal mandrels, arranging the wrapped mandrels with pultruded 
unidirectional-prepreg radius fillers (termed noodles) and placing prepreg facesheets above and below the wrapped mandrels. The entire arrangement was then autoclave co-cured and the mandrels were removed after cure.

The three test-article configurations considered are shown in Fig. 2. Figure 2a shows a coupon-level configuration that is used for the analysis-method validation, and which was discussed in Ref. 5. Figures $2 \mathrm{~b}$ and $2 \mathrm{c}$ show curved-panel and full-cylinder configurations for which the new analysis methodology will be used to make pre-test predictions. The cross sections of the test articles in Fig. 2 are essentially the same except that the test article in Fig. 2a is flat, and the other two are curved. The cross section of these test articles was termed the subscale cross section in Ref. 5, and the experimental testing and detailed analyses of the flat test article are discussed in Ref. 5. The flat test article of Fig. 2a is 12-in. long, 5.39-in. wide on the wide face and 4.87-in. wide on the narrow face, 0.74-in. thick, and consists of five flutes. The curved test article of Fig. $2 \mathrm{~b}$ is 53.875-in. long, has arc-lengths of 31.82-in. on the inner mold line (IML) and 31.63-in. on the outer mold line (OML), is 0.77-in. thick, has a 78.8-in. outer radius, and consists of 33 flutes. The full cylinder shown in Fig. 2c is 112-in. long, has the same radius as the curved panel test article, and consists of five panels connected by longitudinal joints of the type discussed in Ref. 14. For all of the considered test articles, the web layup is [ $\pm 45 / \pm 45]$, and the combined layup of each joined facesheet/flute-span is $[ \pm 45 / 0 / 90]_{s}$. A full set of material properties was not available for the specific toughened carbon-epoxy used in the construction of the test articles, so linear material properties for the similar material IM7/8552 were used in the modeling of all components. ${ }^{15}$

The analysis and analysis results of the test articles shown in Figs. $2 \mathrm{a}$ and $2 \mathrm{~b}$ are reported herein. The analysis of the full-cylinder article is not discussed herein, but is shown as motivation for the currently discussed computationally efficient analysis methodology. Further validation of the analysis methodology will require the experimental testing of these two curved test articles.

\section{Finite-Element Modeling}

The finite-element models used in this study were built using MSC Patran $2010,{ }^{16}$ the analyses were performed with Abaqus/Standard 6.9.1, ${ }^{17}$ and the post processing was completed with Abaqus/CAE 6.9.1. ${ }^{18}$ Two finite-element analysis (FEA) models were developed for each of the panel test articles (Figs. 3a-3d). The flat-panel test article was originally modeled using solid finite elements to represent the pultruded noodles, and with shell elements for all the other components of the panel. ${ }^{5}$ Models using this approach are herein termed solid-noodle models because they use 6-node C3D6 solid wedge elements to represent the pultruded noodles. The facesheets and the flutes were modeled with 4-node S4R5 shell elements. In order to account for important details, and to aid in post processing, the facesheets, flutes, and noodles were modeled using separate components or element sets. Thus the stresses and strains in the facesheets, flutes, and noodles could be easily separated during post processing of the results.

Though excellent agreement with experiment was seen using the solid-noodle method, ${ }^{5}$ this method is not well suited for panels with a larger number of flutes because the model size becomes intractable with large numbers of flutes. Larger elements cannot be used to produce a global model because the wedge elements used in the noodles are sized based on the noodle cross-section dimensions, and the element sizes for the entire model are tied to the smallest face of the wedge elements.

Creating FEA models for larger or more complex structures that are solvable requires an approach different from the solid-noodle approach. The developed approach uses a more computationally efficient model that replaces the solid elements in the noodle with shell elements to form a tee where the webs meet the faces. In this tee region, both the unidirectional noodle and the plies that wrap around the radii of the noodles need to be represented. This is accomplished by varying the thicknesses and offsets of seven laminated shell elements, as shown in Fig. 4. The noodle-region is represented by variable-thickness $0^{\circ}$ plies to model the noodle, and nominal-thickness $+45^{\circ}$ and $45^{\circ}$ plies to model the plies wrapped around the flutes. In order to define the tee using this method, a total of 14 parameters must be chosen - the $0^{\circ}$-ply thickness and the offset for each of the seven shell elements. The parameterized thickness corresponds to the $0^{\circ}$-ply of an element while the offset is a shell-element property that affects all plies. These parameters are chosen such that they define a tee that matches as close as possible the distribution of stiffness-weighted mass and inertia properties of the original section. Because of the demonstrated agreement with experimental testing, the solid-noodle model was used as the standard with which to iteratively tune these parameters. The linear bifurcation buckling loads and modes, and the linear longitudinal shortening are used as the metric for determining agreement between the models. Models using this approach are herein termed shellnoodle models because they use 4-node S4R5 shell elements to represent the pultruded noodle regions. This shellnoodle approach differs from traditional approaches because the shell thicknesses and offsets are parameterized and tuned to produce target mechanical behaviors rather than determined from the design data. A detailed description of this tuning process is given below. Once the parameter-tuning is complete, the shell-noodle model can be used in 
geometrically nonlinear analyses at either local or global levels. The shell-noodle approach was first applied to the flat panel for validation purposes and the results are given in Section III-A. The approach was then used on a 9-flute, 11.875-in long, coupon-model (Figs. 3c and 3d) of the larger 33-flute curved panel (Fig. 2b). The 33-flute panel was modeled with the shell-noodle approach (Fig. 3d) using the parameter values determined for the 9-flute coupon model.

All the models were loaded in longitudinal compression and had the same boundary conditions. One-inch of each end was considered to be potted, and the potting conditions were represented by fixing all rotations and displacements except the longitudinal displacement in the potted regions. Rigid surfaces were fixed to the end cross sections. The bottom rigid surface was fixed in all rotations and displacements, and the top rigid surface was fixed in all rotations and displacements except the longitudinal displacement. A nominal longitudinal-compression load was applied as a longitudinal force on the reference node of the top rigid surface.

The global shell-noodle model may be produced with a coarser mesh than the solid-noodle model because the necessarily small-faced wedge elements are not used. Additionally, eliminating the wedge elements themselves removes additional degrees of freedom, and eliminating the wedge elements saves computational time by removing the three-dimensional solid-element connectivity that produces a less-sparse (and thus more computationally time consuming) system of equations; these savings are particularly important for nonlinear analyses.

Though the shell-noodle model is much more computationally efficient, the global model made with the shellnoodle model would not be able to provide the correct strains and stresses within the noodle. Therefore, the alreadydeveloped solid-noodle model can be used in conjunction with the shell-noodle model by embedding a local solidnoodle model in the global model in one or more places of interest, or by using the results of the global model to produce adequate boundary conditions and loads for the local model. Results of the 9-flute curved-coupon model and of the 33-flute curved panel with and without an embedded local model are given in Section III-B.

\section{A. Modeling and Analysis of the Flat-Panel Test Article}

\section{Shell-Noodle Model Tuning}

Some basic decisions made on this scheme deserve explanation. Because of the noodle shape, it was judged that to avoid an overly stiff response, the number of elements on each of the tee wing sections (elements W1-W4 in Fig. 4) could not be less than two. However, the same cross-sectional length was used for the four elements on the wings because the smallest element length on the cross section determines the number of elements in the longitudinal direction. Similarly, it was believed that using three elements in the tee leg section (elements L1-L3 in Fig. 4) of the noodle was reasonable because three elements on the leg produce elements only slightly longer than those on the wings. Using these seven elements in the shell-noodle produced fourteen unknowns, or parameters, to select. To simplify the parameter tuning, on this test article it was assumed that the leg offsets were zero and that the outer wing elements had equal thickness, so ten unique parameters were left to be chosen. The boundary and loading conditions that were used for the tuning process were for end-potted longitudinal compression, and were identical to those discussed in Ref. 5.

A closed-form solution to determine the thicknesses and offsets would be convenient and might be possible, but currently has not been found. Instead, a heuristic procedure was effectively implemented that started with a guess at a possible solution, and in which the ten remaining parameters were iterated to match results from the solid-noodle model. Once the initial guess was made, a shell-noodle model using the chosen parameter values was produced for bifurcation buckling and linear static analyses. The $0^{\circ}$-ply thicknesses and shell offsets were designated parametric values in the model. In this way, changes could be made in a single file containing the parameters so that the procedure could be scripted if desired. The initial guess used in the current work is made by sketching a distribution of thicknesses and offsets that visually looks equivalent to the physical-noodle cross section. Because some of the ply sections overlap at the junction and because both area and ply longitudinal stiffness are important, this visual equivalence can only be made in a rough manner.

The results that were inspected during the tuning procedure were the first five bifurcation-buckling eigenvalues and eigenmodes and the linear end-shortening. The criteria used to judge agreement were to obtain these five eigenvalues within $1 \%$ of those from the solid-noodle model, and to have the corresponding five eigenmodes appear qualitatively very similar to those of the solid-noodle model. Additionally, the end shortening calculated with the two modeling approaches should be in good agreement for both linear static analyses under the nominal load; comparing the end shortening results ensures that the overall compressive stiffness of the solid-noodle model is well represented by the shell-noodle model. Though these criteria are somewhat arbitrary and deserve investigation, they were chosen because they were thought to be desirably stringent and were able to be met using the heuristic procedure. 
The nominal compression load applied was $20,000 \mathrm{lb}$, and the tuning process took 82 iterations. The resulting solution is shown in Fig. 4 and Table 1. The result was that the tuned shell-noodle model closely mimicked the mechanical behavior of the original solid-noodle. The first five bifurcation-buckling eigenvalues for both solidnoodle and tuned shell-noodle models are shown in Table 2. The critical bifurcation buckling load was the same in both models, 44,844 lb, and the largest relative error for the first five eigenvalues, was $0.26 \%$. In Fig. 5, it is seen that the first two eigenmodes are very similar as well. Comparable agreement was seen for eigenmodes three through five though they are not shown.

To ensure that the correct overall stiffness is well represented by the shell-noodle model, the longitudinal shortening from a linear static analysis under the nominal 20,000-lb load was calculated. By comparing the longitudinal shortening given in Table 3, it is seen that the tuned shell-noodle model was only very slightly stiffer than the solid-noodle model; the longitudinal shortening for the two models was within $3 \%$.

\section{Comparison Between Experimental, and the Solid-Noodle and Shell-Noodle Nonlinear Results}

Because noncatastrophic local facesheet buckling occurred before material failure in the flat-panel test articles, nonlinear analyses are needed to predict the failure response of the flat-panel test articles. A detailed description of the experimental and solid-noodle model results are given in Ref. 5. In the nonlinear analyses of both the solid- and shell-noodle models, a small geometric imperfection that was based on the first linear eigenmode was used with an imperfection amplitude of 0.005 in. These nonlinear analyses were carried out using the built-in Abaqus modified Riks solver so that solutions could be obtained in the postbuckling load range. In this section, selected results from the experiments and the solid- and shell-noodle models are compared. Specifically, comparisons are made of the longitudinal shortening value at the largest load in the nonlinear static analyses, the load vs. longitudinal shortening histories, and the local buckling response. In this paper, the "largest load" for the longitudinal shortening comparisons is the lower of the material-failure load, or the first maximum in the load vs. displacement plot. Material failure is predicted using the maximum-stress failure criterion, and the material-failure loads are taken to be the first available load increment where a material strength has been exceeded.

The first comparison is the longitudinal shortening at the largest load of the nonlinear static analyses (Table 3) of the flat panel. The largest loads reached in the two nonlinear flat-panel analyses were material failure loads and were within $1.3 \%$ of each other. At these loads, the end shortening values agreed within $0.5 \%$. Comparison of the load vs. end-shortening histories from nonlinear-static analysis of both flat-panel solid-noodle and shell-noodle models showed that the loads were within $1.5 \%$ of each other at all end-shortening values. Additionally, the experimental slopes of the load vs. end-shortening curves calculated between 14,000 and 32,000 lb (the range after initial experimental nonlinearity and before local buckling) were within $4.5 \%$ of both analyses. Discrepancies may have been caused by the actual geometry and material imperfections in the tested panels, and by modeling the potted ends of the panel as having a transversely rigid potting material. These sources of error might also be responsible for the larger half-wave count in the model, which in general was slightly stiffer than the tested articles.

Figure 6 shows the fully developed local buckling in one of the experimental test articles just prior to material failure $(53,500 \mathrm{lb})$. It is seen that local-buckling half waves formed in each of the flute wide spans, so that there were two columns of half waves on the back side, and three columns of half waves on the front side. For comparison, predicted out-of-plane displacements at a 53,100-lb compressive load from the nonlinear-static analysis on front face of the solid-noodle and shell-noodle models are displayed in Fig. 7, where positive displacements are outward. Observation of Figs. 6 and 7 shows good qualitative agreement between the experiment and both finiteelement models. However, it is seen that nine longitudinal half waves developed in the experiment, but 11 half waves developed in both the analyses. For quantitative comparison between the two finite-element models, consider that there is very little difference in the displacement values given in Fig. 7. The black contours on Fig. 7b (the shellnoodle model) represent areas where the displacements were slightly higher than the maximum in the scale (which was set by the maximum and minimum displacements calculated for the solid-noodle model of Fig. 7a), and indicate the slight differences between the two results. Though not shown, other predicted strain- and stress-fields for the two models were also nearly indistinguishable.

The nonlinear static analysis provided insight on other qualitative behavior as well. For example, "dimples" (small round sunken areas) near the end of the potting sections on both faces were the first-observed significant outof-plane deformations during the physical tests. This dimpling behavior was also predicted by both the solid-noodle and shell-noodle models.

It can thus be affirmed that linear buckling analyses and geometrically nonlinear static analyses showed excellent agreement between the solid-noodle model, the shell-noodle model, and experiments for the configuration shown in Fig. 2a. Additionally, even for this small flat panel, the shell-noodle model is much more computationally efficient than the solid noodle model. This efficiency can be demonstrated by comparing the number of degrees of freedom 
and CPU times used by both models. The solid-noodle model had 178,038 degrees of freedom and used 8,246 seconds of CPU time on a desktop PC for the nonlinear static analysis. The corresponding shell-noodle model had 134,874 degrees of freedom and the nonlinear analysis used 4,536 seconds of CPU time on the same computer. This saving of about $25 \%$ in model size and $45 \%$ in CPU time was achieved without using a coarser mesh in the shellnoodle model. However, the ability to use a coarser mesh is precisely one of the advantages of the technique, and would produce even greater savings.

\section{B. Modeling and Analysis of the Curved-Panel Test Article \\ 1. Comparison of Solid- and Shell-Noodle Coupon Models}

The method described in the previous section was repeated with the curved-panel shown in Fig. $2 \mathrm{~b}$. That is, both solid-noodle and shell-noodle models were created, and the shell-noodle model was tuned using both bifurcationbuckling and linear-static analyses run on both models. However, the tuning was performed on coupon models having the same cross-sectional geometry as the full curved-panel test article, and several refinements that are discussed below were made to improve the shell-noodle model. The coupon models, shown in Figs. 3c and 3d, consist of nine flutes and are 11.875-in. long. These coupon models had identical boundary conditions to those described for the flat panel, but the nominal compression load used was 10,000 $\mathrm{lb}$.

The same concept of developing a shell-noodle model that incorporates the flute plies adjacent to the curved sides of the actual pultruded noodle was used. As before, seven-element sets were defined with two elements on each wing of the resulting tee joint, and three elements on the on the leg. Therefore, there were fourteen unknowns - namely the seven thicknesses and the seven offsets of those element sets.

The representation of the pultruded noodle was similar in proportion to that in the flat-panel model, but was modified to more-accurately represent the experimental test articles. The leg of the tee in this equivalent shellnoodle model was cylindrical so that it would roughly bisect the actual noodle section, as shown in Fig. 8, which shows several relevant technical matters. It is seen that the shell noodle can easily replace the solid noodle because the outer nodes of the tee connect to the spans and webs of the flutes on their edges. Because the leg of the noodle is cylindrical, it has a cylindrical coordinate system that provides the same type of shell property control as in the flat segments of the tee region. Additionally, the issue of excessive participation of the $\pm 45^{\circ}$ plies in the shell noodle was addressed by incorporating a fifteenth parameter - the thickness of the $\pm 45^{\circ}$ plies in the L1 elements. It is expected that this thickness will be reduced to an almost negligible value. This parameter may be understood by referring to Fig. 4 where it can be seen that adding the length of the three leg elements and the two wing elements on each side results in a length that exceeds the arc length of the $\pm 45^{\circ}$ plies in the solid-noodle model. By nearly removing the contribution of the $\pm 45^{\circ}$ plies in the L1 leg element, the remaining four elements approximate the original length.

Bifurcation-buckling and linear-static analyses were run using the solid- and shell-noodle coupon models as the thickness and offset parameters were varied to iteratively tune the shell-noodle model. The iterative process was similar to the one described for the flat-panel models. It has been shown that the effective transverse shear stiffness of fluted-core structures can significantly affect structural response, ${ }^{9}$ so in addition to the axial compressive load and associated boundary conditions, a second load case simulating circumferential transverse-shear loading was used in the tuning process. The load introduction was different in the transverse-shear load case than in the previous axialcompression cases. In the transverse-shear load case, rigid surfaces were attached along the entire length of the panel on the regions designated $\mathrm{A}$ and $\mathrm{B}$ in Figs. $3 \mathrm{c}$ and $\mathrm{d}$. The rigid surface on region $\mathrm{B}$ was fixed in all degrees of freedom, and the rigid surface in region A was fixed in all degrees of freedom except circumferential displacement. To introduce the load, a circumferential force was applied to the rigid surface in region A to apply transverse shear to the coupon. These conditions were applied to both the solid-noodle and shell-noodle models. Bifurcation buckling results for both compression and transverse shear loading, in conjunction with linear static compression analyses results, were used in the heuristic approach to finding appropriate values for the fifteen parameters in the shellnoodle model. Considering transverse shear during the tuning procedure is important because the transverse shear stiffness can be very important in accurately capturing the global buckling behavior of the full barrel of Fig. 2c. ${ }^{9}$ Linear static results from the transverse shear model and a third distinct condition, axial-shear (that was not included in the parameter-optimization procedure), are discussed below.

The tuned parameter values found using both the compression-loaded and transverse-shear models are shown in Table 4. Figure 9 shows the first compression buckling mode predicted from these two models, which correspond to a critical bifurcation-buckling load of $65,700 \mathrm{lb}$ in both models. The first five eigenvalues from the solid- and shellnoodle models for the compression load matched within $0.25 \%$, and the first eigenvalue matched within $0.1 \%$. The eigenmodes also agreed well. The linear static analyses were run with the nominal compression load of 10,000 lb. Selected results from the linear and nonlinear static compression analyses are given in Table 5. The corresponding panel shortenings calculated on both solid-noodle and shell-noodle models were identical at 0.0106 in. The 
nonlinear static analyses predicted material failure at 39,300 lb for the solid-noodle model and 39,700 $\mathrm{lb}$ for the shell-noodle model. These loads were within $1 \%$ of each other and greater than the local buckling loads, but lower than any global panel buckling, so they are within the range where the load-shortening curves are fairly linear. The two models produced nearly identical load-shortening histories, with loads staying within $0.5 \%$ of each other throughout the simulation. The axial shortening values matched within $2 \%$ at the material-failure loads.

The contour plots in Fig. 10 show the fiber-oriented (axial) stress fields on top of the outermost $0^{\circ}$ ply on both the IML and OML facesheets on both models at their respective material failure loads from the compressive nonlinear static analysis. It is seen that there is very good agreement between the solid- and shell-noodle models over the entire surfaces. There are small visual differences between corresponding contour plots, particularly near the potted area and on the potting area themselves, but those differences are small (less than 200 psi) at any point. Failure is predicted to occur on each edge where the potted sections end.

The transverse-shear case that was used in the tuning had the circumferential force applied toward the fixed edge; that is, it was a pushing transverse-shear case. Linear- and nonlinear-static results are given in Table 6; the solid- and shell-noodle displacements of the shell-noodle were within $1.5 \%$ for the linear analyses at a nominal $1,000 \mathrm{lb}$ load, and within $2.6 \%$ for the nonlinear analyses at the largest load. The largest load in the nonlinear analysis was, in this case, the first maximum in the load vs. displacement plot, and was 2,740 lb for both models. The critical bifurcation-buckling load was calculated to be 4,932 lb with the solid-noodle model and 4,997 lb (1.33\% higher) with the shell-noodle model. The first six eigenvalues from the shell-noodle model were all within $4.52 \%$ of those from the solid-noodle model. The eigenmodes also matched well, but the $5^{\text {th }}$ and $6^{\text {th }}$ modes were switched in the two models; these two eigenvalues were within $3.6 \%$ of their average value of 10,478 $\mathrm{lb}$.

Though the shell-noodle model was adjusted using the axial compression loading and pushing circumferential transverse-shear loading conditions, the resulting model was also exercised under two other loading conditions. The first of these additional loading conditions was a pulling circumferential transverse-shear case, which was produced by simply reversing the load used in the previously discussed pushing transverse-shear case; all other conditions were the same. The second additional case was a distinct pushing axial transverse-shear case. In the axial transverse-shear load case, one-inch long rigid surfaces were attached over the entire width of one face of each panel end. One of these rigid surfaces was attached to inner face, and the other rigid surface was attached to the outer face. The rigid surface on the inner face was fixed in all degrees of freedom, and the rigid surface on the outer face was fixed in all degrees of freedom except axial displacement. To introduce the load, an axial force was applied to the rigid surface in the outer face to apply axial transverse shear to the coupon.

The bifurcation-buckling modes under the pulling circumferential transverse shear loading are the same as those discussed above under the pushing conditions, but the eigenvalues have the opposite sign. Additionally, linear static analyses also produce the same displacements with opposite sign. However, the predicted behaviors are different in nonlinear static analyses. This is because on this panel, in the pushing case the faces buckle first, while in the pulling case the webs buckle first. In this pulling case, the maximum loads are 3,900 lb for the solid-noodle model and $3,850 \mathrm{lb}$ for the shell-noodle model (1.3\%. lower). At these maximum loads, the predicted displacements were both 0.0277 in.

Under the pushing axial transverse-shear loading, the first five eigenvalues from the solid- and shell-noodle models matched within $0.31 \%$, and the eigenmodes were also very similar. The predicted displacements from the solid- and shell-noodle models matched within $1.7 \%$ for linear static analysis under a 10,000-lb load. The predicted loads from the solid- and shell-noodle nonlinear static analyses matched within $2.9 \%$ at the large applied displacement of 0.0797 in.

\section{Global-Local Analyses}

After the parameter tuning was complete and the already discussed additional load cases were examined with the coupon models, a global shell-noodle model was created for the curved test article of Fig. $2 \mathrm{~b}$ using the same tuned thickness and offset parameters and cross-sectional geometry as the curved coupon shell-noodle model. This global shell model was used to make pre-test predictions for the curved-panel test article (Fig. 2b) under uniform axial compression. The cross section of this model is shown in Fig. 3b. The setup of boundary conditions and loading for the global model is the same as that used for the axial-compression loading of the flat panel and curved-coupon panel; that is, the edges were free, 1 in. of each end was considered potted, and the ends had applied rigid surfaces that were used to introduce the load. However, as can be seen in Fig. 2b and illustrated in Fig. 11, the curved panel, and thus its global model, also includes a padup on the ends of the panel. The padup consists of eight pre-cured and secondarily bonded plies with the same layup as the faces (with the flute plies), and is identical on both top and bottom and inner and outer faces. To transition to the test section of the panel, pairs of the padup plies are dropped 
as shown in Fig. 11. In the model, the additional padup plies are incorporated into the existing element properties so no additional mesh elements or degrees of freedom were required to represent the padups.

For pretest predictions, both bifurcation buckling and geometrically nonlinear static analyses under compression loading were performed using the global shell-noodle model. For the bifurcation-buckling analysis, the nominal compression load applied for the global model of the curved panel was 100,000 lb applied as an axial force on the reference node of the top rigid surface. Table 7 gives the first ten eigenvalues. The first four eigenmodes are global modes and are shown in Fig. 12. The first bifurcation buckling mode is nearly antisymmetric and corresponds to a critical bifurcation-buckling load of 122,700 lb. The second mode, shown in Fig. 12b, is symmetric and corresponds to a load of $123,200 \mathrm{lb}$, only $0.4 \%$ higher than the critical one. The third and fourth modes, (Fig. 12c and d) corresponded to clearly higher loads. All first four modes are of global nature. The fifth mode, shown in Fig. 13, is the first local eigenmode.

A geometrically nonlinear static analysis was used to predict the postbuckling responses of the curved panel. The first eigenmode was used as an initial geometric imperfection with the small amplitude of $0.005 \mathrm{in}$. The predicted axial stresses in two of the $0^{\circ}$ plies at $81,000 \mathrm{lb}$ compression are shown in Fig. 14. This figure shows that the panel deformed into a basically symmetric mode similar to the second eigenmode shown previously, that the inner (concave) face has higher stresses than the outer face, and that first material failure is predicted (using the maximum-stress failure criterion) to occur on one of the edges of the inner face at the midlength. The effect of padup ply drops is evident in the staggered contour-plot color changes near the panel ends.

The solid-noodle coupon model that was used for the tuning can be embedded as a local model anywhere within this global model to create a global-local representation. The solid noodles and shell noodles are connected via multiple-point constraints (MPCs). The solid-noodle coupon model was embedded in the center of the edge of the shell-noodle global model of the curved-panel test article (Fig. 15) because this is where the failure was predicted to occur using the shell-noodle model. The predicted axial stresses from this global-local model under 81,000 lb axial compression in $0^{\circ}$ plies on the inner and outer face are shown in Fig. 15. This figure can be directly compared with Fig. 14, and it shows that the stresses are reasonably continuous in the transition between the shell- and solid-noodle regions with local "spots" exhibiting acceptable deviations in the stress magnitudes around the locations of connectivity between the solid- and shell-noodle sections. The maximum fiber-oriented stress on the global-local model (Fig. 15) is smaller (within a 1\%) than the corresponding maximum in the global (shell-noodle only) model (Fig. 14). That maximum stress appeared on the opposite edge because the local solid-noodle sections are slightly stiffer than the shell-noodle counterpart they replace in the global model. The overall distribution of stresses remains very much the same as can be seen when comparing Figures 14 and 15.

The free-edge conditions used on the global model correspond to the proposed test of the curved panel of Fig. 2b. However, the full barrel of Fig. 2c is a closed shell, so the panels in it have their edges supported. It will need to be determined whether local buckling will be the first failure mode, and how close it is to the other failure modes. Therefore, the response of the curved panel under axial compression with supported edges was examined as a way to activate the local buckling response. The supported edges were modeled by considering the edges potted, so that the motion of the side webs and the outer underside and top of the edge noodles are fixed in all directions except axial displacement. With the same nominal axial compression load of $100,000 \mathrm{lb}$ in a bifurcation-buckling analysis, the resulting first ten eigenmodes were all local buckling modes, with eigenvalues all within $0.55 \%$ of the first eigenvalue. The critical buckling mode is a local mode, and the critical buckling load is predicted to be $222,230 \mathrm{lb}$, which is, as expected, much higher than the critical load for the free-edge model. As a potential imperfect geometry for nonlinear analyses, the first eight eigenvalues, which are within 5\% of the first, were combined by adding their corresponding normalized modes and are shown in Fig. 16. Note that in Fig. 16 each of the combined modes had a maximum amplitude of 1.0 in., but in practice smaller normalized amplitudes would be used to produce a combinedmode imperfection with reasonable amplitude.

By considering both the free-edge and supported-edge conditions, it is shown that the same efficient model (albeit with different boundary conditions) can be used to predict behaviors at both the local and global scales.

\section{Concluding Remarks}

Fluted-core composite structures may have benefits for certain launch vehicle structures. However, in order to efficiently evaluate fluted-core structures, computationally efficient analysis methodologies must be available. One such methodology that handles an important structural detail in a novel way is discussed herein. This methodology uses shell elements to capture behavior that would normally require solid elements. The thicknesses and the offsets of these shell elements are chosen to match the stiffness-weighted moments of inertia of the solid elements they would replace, and then iterated until the linear buckling modes and loads match well with more detailed models. 
Experiments and detailed models of coupon panels were used to validate the methodology, and excellent agreement was found between all the results. Additionally, the utility of the method was demonstrated by examining the compression behavior of a larger curved panel, and it was seen that both local and global responses could be captured using the same approach. Though the methodology is discussed in the context of fluted-core composites, it is also applicable to other built-up shell structures.

\section{Acknowledgments}

This work was conducted as part of the NASA Engineering and Safety Center (NESC) Shell Buckling Knockdown Factor Project, NESC assessment number 07-010-E. All test articles discussed herein were produced and provided by The Boeing Company.

\section{References}

${ }^{1}$ Anonymous, “Ares I First Stage, Powering NASA's Newest Rocket,” NASA Facts, FS-2008-05-86-MSFC.

${ }^{2}$ Anonymous, "NASA's Ares I Upper Stage, Powering the Second Phase of a Rocket's Journey to Space," NASA Facts, FS2009-08-153-MSFC.

${ }^{3}$ Anonymous, “Constellation Program: America's Fleet of Next-Generation Launch Vehicles, The Ares V Cargo Launch Vehicle,” NASA Facts, FS-2009-07-134-MSFC.

${ }^{4}$ Nettles, A. and Jackson, J., "Compression After Impact Testing of Sandwich Composites for Usage on Expendable Launch Vehicles," Journal of Composite Materials, Vol. 44, No. 6, 2010, pp. 707-738.

${ }^{5}$ Schultz, M.R., Oremont, L., Guzman, J.C., McCarville, D., Rose, C.A., Hilburger, M.W., "Compression Behavior of FlutedCore Composite Panels," Proceedings of the $52^{\text {nd }}$ AIAA/ASME/ASCE/AHS/ASC Structures, Structural Dynamics, \& Materials Conference, AIAA paper no. 2011-2170, Denver, CO, April 2011.

${ }^{6}$ Egle, D.M. and Sewall, J.L., "An Analysis of Free Vibration of Orthogonally Stiffened Cylindrical Shells with Stiffeners Treated as Discrete Elements", AIAA Journal, Vol. 6, No. 3, 1968, pp. 518-526.

${ }^{7}$ Singer, J., Arbocz, J, and Babcock, C.D., "Buckling of Imperfect Stiffened Cylindrical Shells under Axial Compression”, AIAA Journal, Vol. 9, No. 1, 1971, pp. 68-75.

${ }^{8}$ Thornburg, R.P. and Hilburger, M.W., "Longitudinal Weld Land Buckling in Compression-Loaded Orthogrid Cylinders," NASA/TM-2010-216876, December 2010.

${ }^{9}$ Lovejoy, A.E. and Schultz, M.R., "Evaluation of Analysis Techniques for Fluted-Core Sandwich Cylinders," Proceedings of the 53 ${ }^{\text {rd }}$ AIAA/ASME/ASCE/AHS/ASC Structures, Structural Dynamics, \& Materials Conference, Honolulu, HI, April 2012.

${ }^{10}$ Lok, Tat-Seng, "Elastic Stiffness Properties and Behavior of Truss-Core Sandwich Panels," Journal of Structural Engineering, May 2000, pp. 552-559.

${ }^{11}$ Martinez, O., Bapanapalli S., Sankar, B., and Haftka, R, "Micromechanical Analysis of Composite Truss-core Sandwich Panels for Integral Thermal Protection Systems," Proceedings of the 47 ${ }^{\text {rd }}$ AIAA/ASME/ASCE/AHS/ASC Structures, Structural Dynamics, \& Materials Conference, Newport, RI, May 2006.

${ }^{12}$ Sharma, S., Sankar, B.V., and Haftka, R.T, "Homogenization of Plates with Microstructure and Application to Corrugated Core Sandwich Panels," Proceedings of the $51^{\text {st }}$ AIAA/ASME/ASCE/AHS/ASC Structures, Structural Dynamics, \& Materials Conference, Orlando, FL, April 2010.

${ }^{13}$ De Rosa, V., Friis, J., and Louca, L.A., "Nonlinear Analysis of Stainless Steel Corrugated Panels Under Blast Loading: A Numerical Study," Imperial College of Science, Technology and Medicine Research Report Number 103, Prepared for the U.K. Health and Safety Executive (HSE), Norwich, U.K., 2003.

${ }^{14}$ Schultz, M.R., Rose, C.A., Guzman, J.C., McCarville, D., Hilburger, M.W., "Experimental Study of the Compression Response of Fluted-Core Composite Panels with Joints," Proceedings of the $53^{\text {rd }}$ AIAA/ASME/ASCE/AHS/ASC Structures, Structural Dynamics, \& Materials Conference, Honolulu, HI, April 2012.

${ }^{15}$ Reeder, James R., "Property Values for Preliminary Design of the Ares I Composite Interstage,” Memo, 14 March 2007, pg. 7, Table $1,1^{\text {st }}$ column.

${ }^{16}$ MSC Patran 2010, Software Package, MSC.Software Corporation, Santa Ana, CA, 2010.

${ }^{17}$ Abaqus/Standard, Software Package, Ver. 6.9.1, SIMULIA, Providence, RI, 2009.

${ }^{18}$ Abaqus/CAE, Software Package, Ver. 6.9.1, SIMULIA, Providence, RI, 2009. 
Table 1. Flat-panel equivalent-shell properties by element position within noodle.

\begin{tabular}{|l|c|c|c|c|c|c|c|c|c|}
\hline \multicolumn{1}{|c|}{ Property } & W1 & W2 & W3 & W4 & L1 & L2 & L3 & W1 W2 W3 W4 \\
\hline $\begin{array}{l}0^{\circ} \text { ply } \\
\text { thickness (in.) }\end{array}$ & 0.0056 & 0.0280 & 0.0168 & 0.0056 & 0.0728 & 0.0280 & 0.0030 & L1 \\
\hline $\begin{array}{l}\text { Shell fractional } \\
\text { offset* }\end{array}$ & 0.9000 & 1.2000 & 1.0000 & 0.9000 & 0.0000 & 0.0000 & 0.0000 & L2 \\
\hline
\end{tabular}

*Offset normalized by the total shell thickness.

Table 2. Flat panel solid-noodle and shell-noodle bifurcation-buckling analysis results under longitudinalcompression loading.

\begin{tabular}{|r|r|r|r|}
\hline \multirow{2}{*}{ Mode } & \multicolumn{1}{|c|}{$\begin{array}{c}\text { Solid noodle } \\
\text { model }\end{array}$} & $\begin{array}{c}\text { Shell noodle } \\
\text { model }\end{array}$ & \multirow{2}{*}{$\begin{array}{c}\text { Eigenvalue ratio } \\
\text { (shell/solid) }\end{array}$} \\
\cline { 2 - 3 } & \multicolumn{2}{|c|}{ Eigenvalue } & 1.0000 \\
\hline 1 & 2.2422 & 2.2422 & 0.9985 \\
\hline 2 & 2.2460 & 2.2426 & 1.0001 \\
\hline 3 & 2.2624 & 2.2645 & 0.9981 \\
\hline 4 & 2.2727 & 2.2683 & 1.0026 \\
\hline 5 & 2.2737 & 2.2795 & \\
\hline
\end{tabular}

Table 3. Flat panel solid-noodle and shell-noodle static analysis results under longitudinal-compression loading.

\begin{tabular}{|l|r|r|r|}
\hline \multirow{2}{*}{ Model } & \multicolumn{2}{|c|}{ Linear static } & \multicolumn{2}{|c|}{ Nonlinear static } \\
\cline { 2 - 4 } & $\begin{array}{c}\text { Longitudinal shortening } \\
\text { at 20,000 lb (in.) }\end{array}$ & $\begin{array}{c}\text { Material-failure } \\
\text { load (lb) }\end{array}$ & $\begin{array}{c}\text { Longitudinal shortening at } \\
\text { material-failure load (in.) }\end{array}$ \\
\hline Solid-noodle & 0.0313 & 54,586 & 0.0898 \\
\hline Shell-noodle & 0.0304 & 55,288 & 0.0894 \\
\hline
\end{tabular}

Table 4. Curved-panel equivalent-shell properties by element position within noodle.

\begin{tabular}{|c|c|c|c|c|c|c|c|c|}
\hline Property & W1 & $\mathrm{W} 2$ & W3 & W4 & $\mathrm{L} 1$ & $\mathrm{~L} 2$ & L3 & \multirow{4}{*}{$\begin{array}{llll}\text { W1 } & \text { W2 } & \text { W3 } & \text { W4 }\end{array}$} \\
\hline $\begin{array}{l}0^{\circ} \text { ply } \\
\text { thickness (in.) }\end{array}$ & 0.00601 & 0.01226 & 0.01226 & 0.00601 & 0.07500 & 0.04700 & 0.00200 & \\
\hline $\begin{array}{l}\text { Shell fractional } \\
\text { offset }(*)\end{array}$ & 0.99038 & 1.25000 & 1.25000 & 0.90000 & 0.06000 & 0.00268 & 0.30000 & \\
\hline $\begin{array}{l}45^{\circ} \text { ply } \\
\text { thickness (in.) }\end{array}$ & 0.00560 & 0.00560 & 0.00560 & 0.00560 & 0.00014 & 0.00560 & 0.00560 & \\
\hline
\end{tabular}

(*) The fractional offset is computed as a ratio to total shell thickness. 
Table 5. Curved-coupon panel solid- and shell-noodle static analysis results under axial-compression loading.

\begin{tabular}{|l|r|r|r|}
\hline & \multicolumn{1}{|c|}{ Linear static } & \multicolumn{2}{|c|}{ Nonlinear static } \\
\cline { 2 - 4 } \multicolumn{1}{c|}{ Model } & $\begin{array}{c}\text { Axial shortening at } \\
10,000 \mathrm{lb} \text { (in.) }\end{array}$ & $\begin{array}{c}\text { Material-failure } \\
\text { load (lb) }\end{array}$ & $\begin{array}{c}\text { End shortening } \\
\text { at material-failure load (in.) }\end{array}$ \\
\hline Solid-noodle & 0.0106 & 39,300 & 0.0418 \\
\hline Shell-noodle & 0.0106 & 39,700 & 0.0425 \\
\hline
\end{tabular}

Table 6. Curved-coupon panel solid-noodle and shell-noodle static analysis results under pushing transverse-shear loading.

\begin{tabular}{|c|r|r|r|}
\hline \multirow{2}{*}{ Model } & Linear static & \multicolumn{2}{|c|}{$\begin{array}{c}\text { Nonlinear static } \\
\text { (at largest load) }\end{array}$} \\
\cline { 2 - 4 } & $\begin{array}{c}\text { Displacement at } \\
1,000 \text { lb (in.) }\end{array}$ & Largest load (lb) & $\begin{array}{c}\text { Displacement at } \\
\text { largest load (in.) }\end{array}$ \\
\hline Solid-noodle & 0.00800 & 2,740 & 0.0270 \\
\hline Shell-noodle & 0.00812 & 2,740 & 0.0263 \\
\hline
\end{tabular}

Table 7. Bifurcation-buckling results of free-edge and potted, 33-flute curved-panel model under an axial compression load of $100,000 \mathrm{lb}$.

\begin{tabular}{|r|r|r|}
\hline \multicolumn{1}{|c|}{ Mode } & Type & \multicolumn{1}{c|}{ Eigenvalue } \\
\hline 1 & global & 1.2163 \\
\hline 2 & global & 1.2320 \\
\hline 3 & global & 1.7418 \\
\hline 4 & global & 1.8199 \\
\hline 5 & local & 2.3287 \\
\hline 6 & local & 2.3287 \\
\hline 7 & local & 2.3298 \\
\hline 8 & local & 2.3310 \\
\hline 9 & local & 2.3340 \\
\hline 10 & local & 2.3346 \\
\hline
\end{tabular}




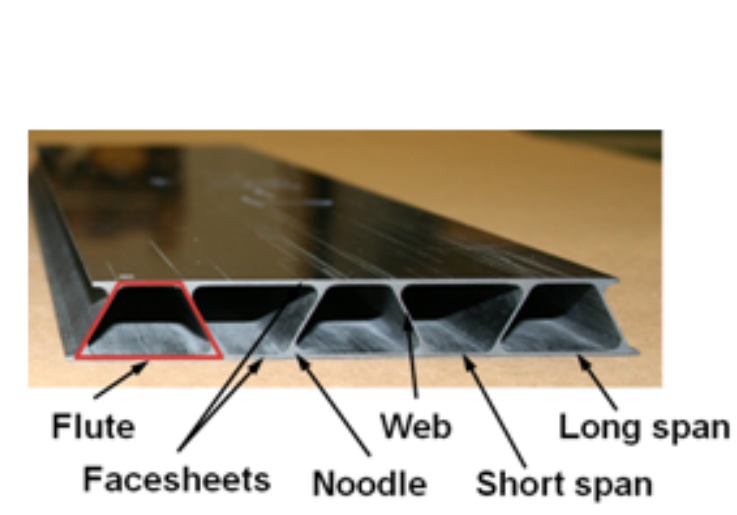

(a) Cross section and nomenclature

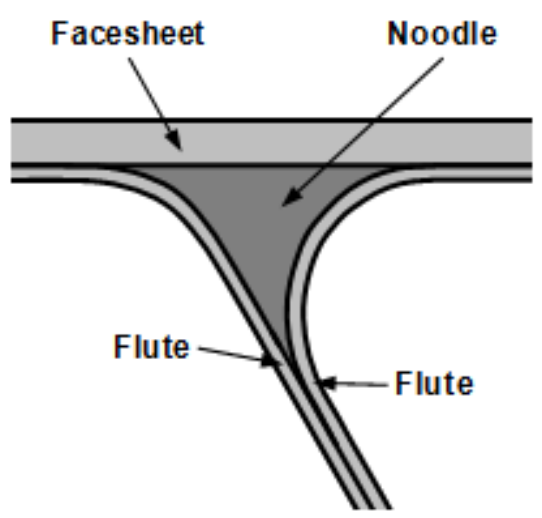

(b) Cross-sectional sketch

Figure 1. Cross section.

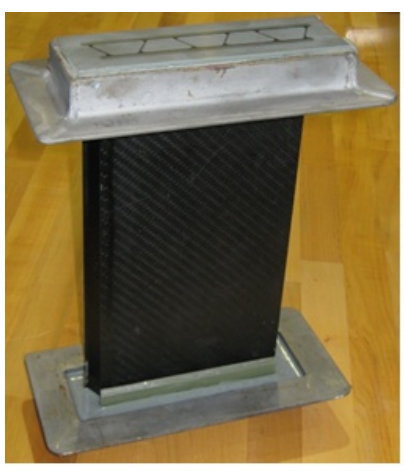

(a) Flat panel

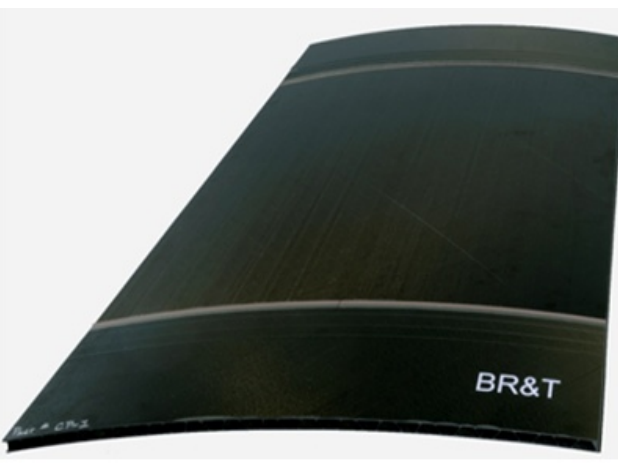

(b) Curved panel

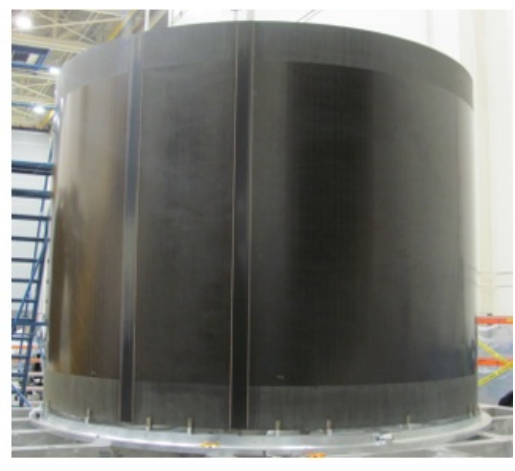

(c) Full cylinder (photo courtesy of The Boeing Company)

Figure 2. Test articles. 


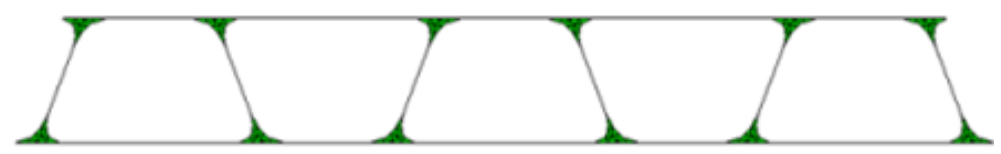

(a) Flat-panel solid-noodle cross section

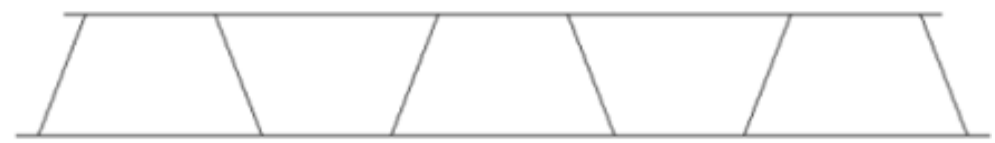

(b) Flat-panel shell-noodle cross section

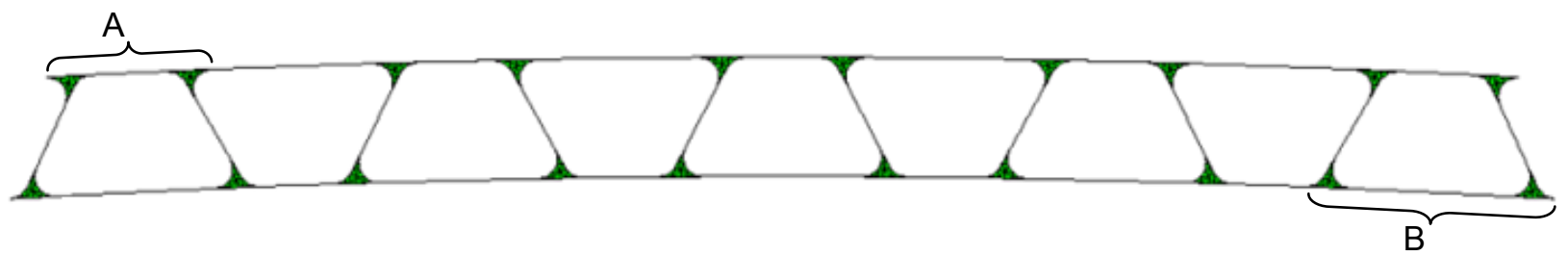

(c) Curved-panel local solid-noodle cross section

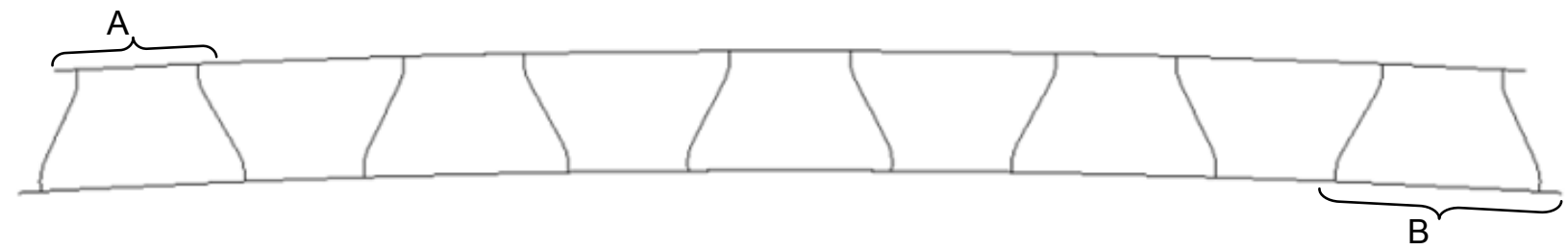

(d) Curved-panel local shell-noodle cross section

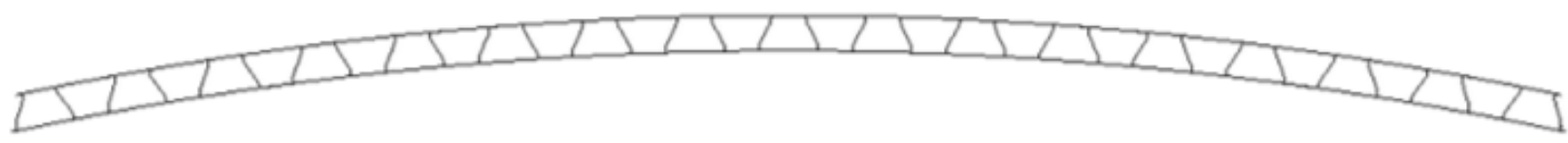

(e) Curved-panel global shell-noodle cross section (shown in different scale)

Figure 3. Cross sections of finite-element meshes for analysis of the fluted-core test articles. 


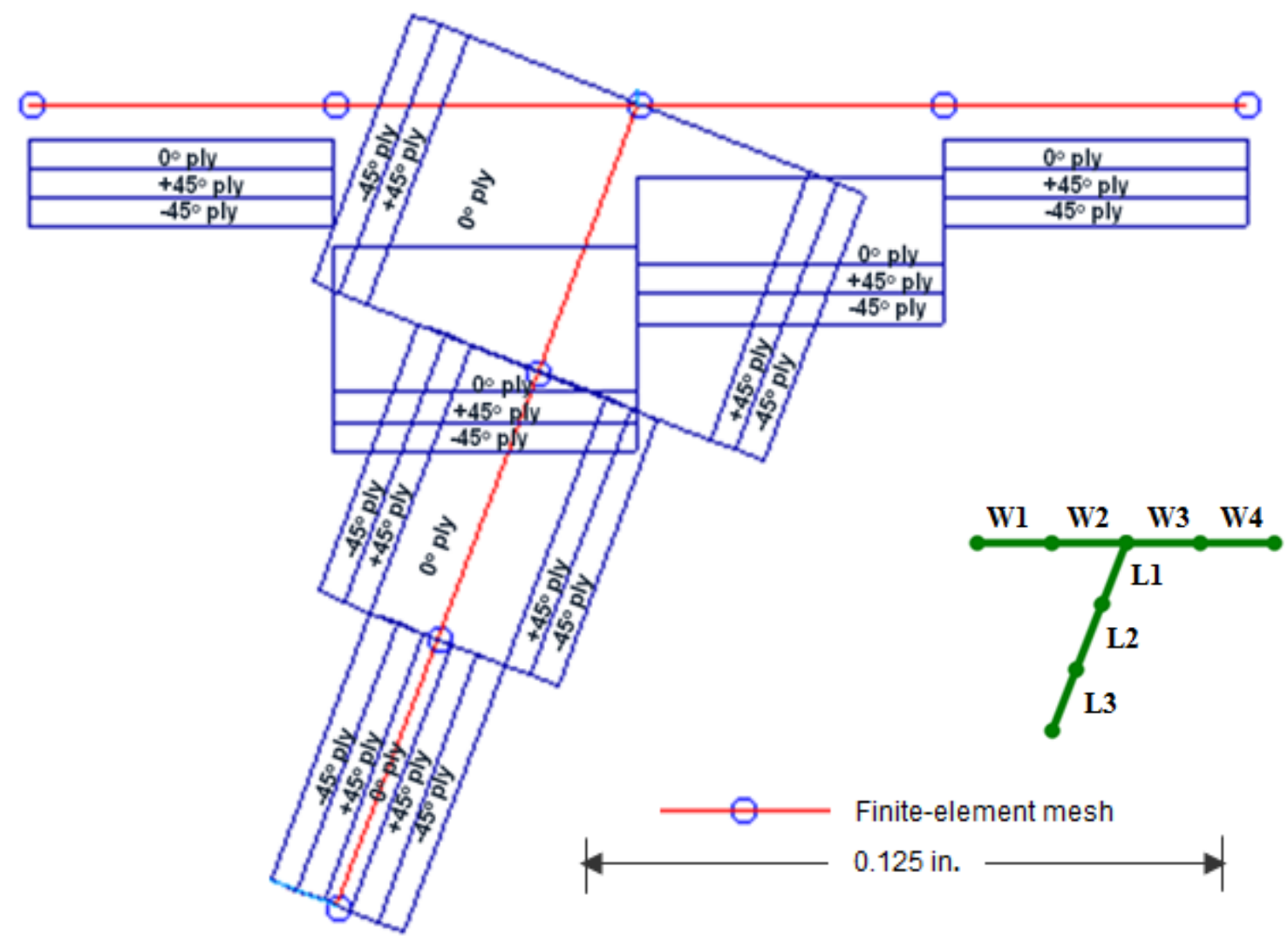

Figure 4. Shell-noodle model of the noodle region showing layups, thicknesses, and offsets. 


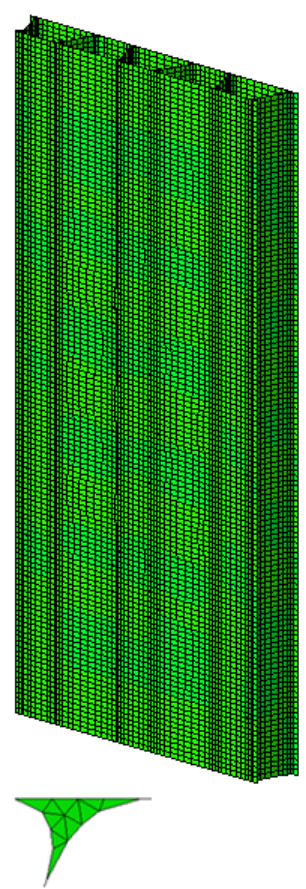

Mode 1: Eigenvalue $=2.4222$

Solid-noodle model
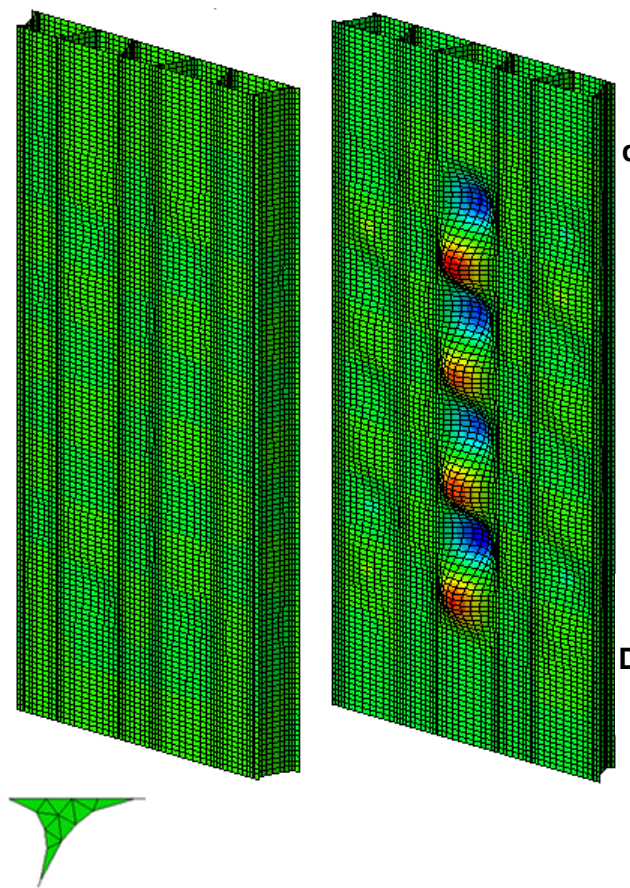

Mode 2: Eigenvalue $=2.2460$

Solid-noodle model

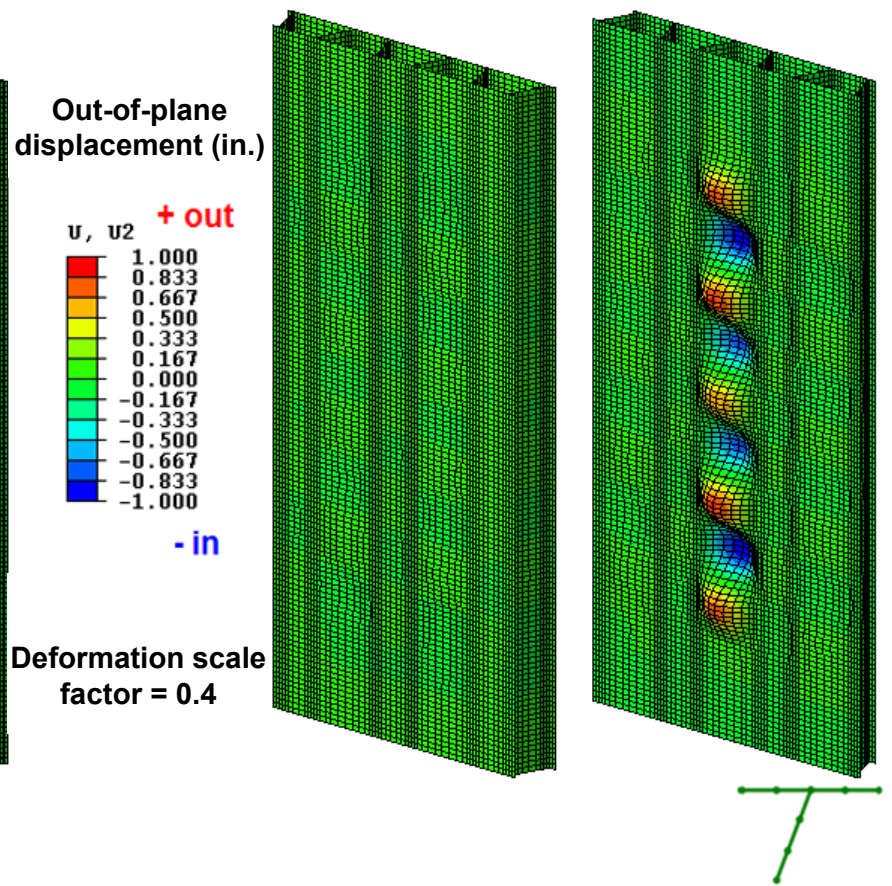

Mode 1: Eigenvalue $=2.4222$

Shell-noodle model

(a) First mode

Out-of-plane displacement (in.)

$$
\begin{aligned}
& \text { v, v2 + out } \\
& \text { - in }
\end{aligned}
$$

\section{Deformation scale} factor $=0.4$

(b) Second mode
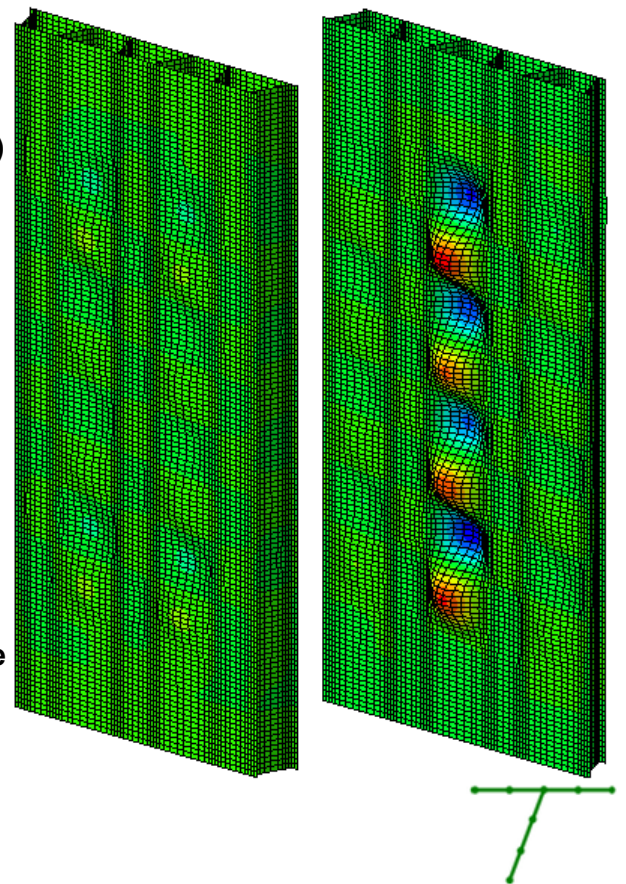

Mode 2: Eigenvalue $=2.2426$ Shell-noodle model

Figure 5. First and second bifurcation-buckling mode of flat-panel models under compression loading. 


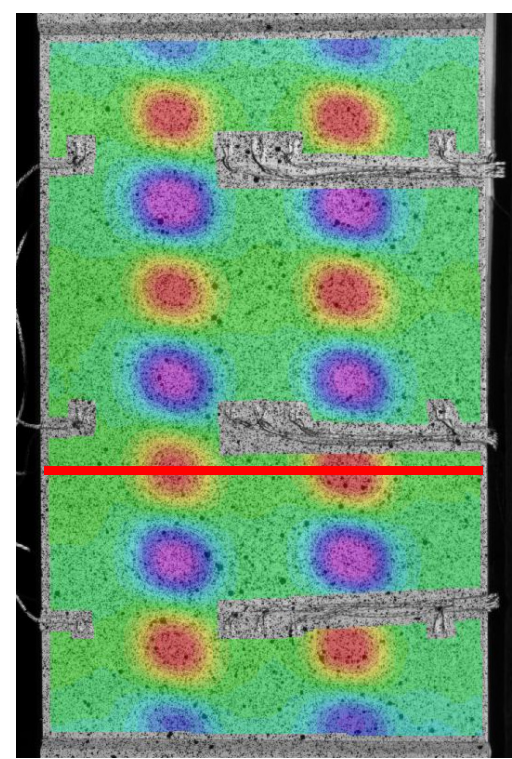

(a) Back

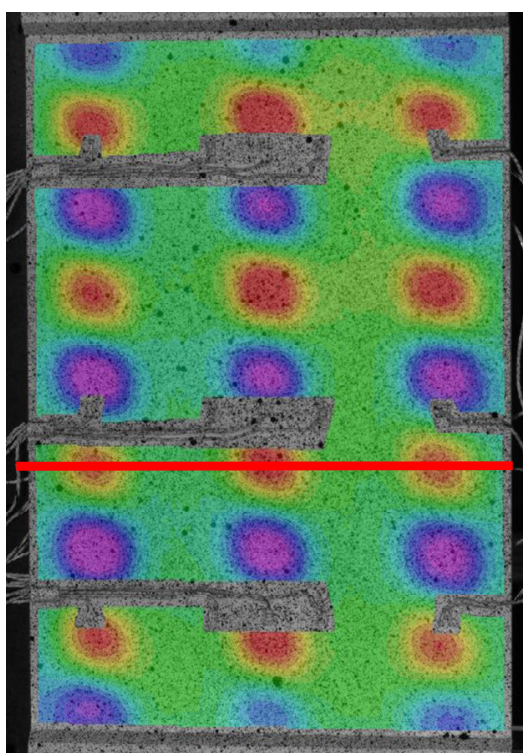

(b) Front
Displacement

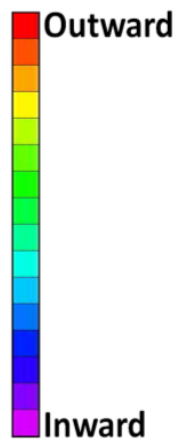

-Failure

Figure 6. Experimental out-of-plane displacements at 53,500 lb applied compressive load from flat-panel CPA-2B. Red lines indicate the location of final panel failure.

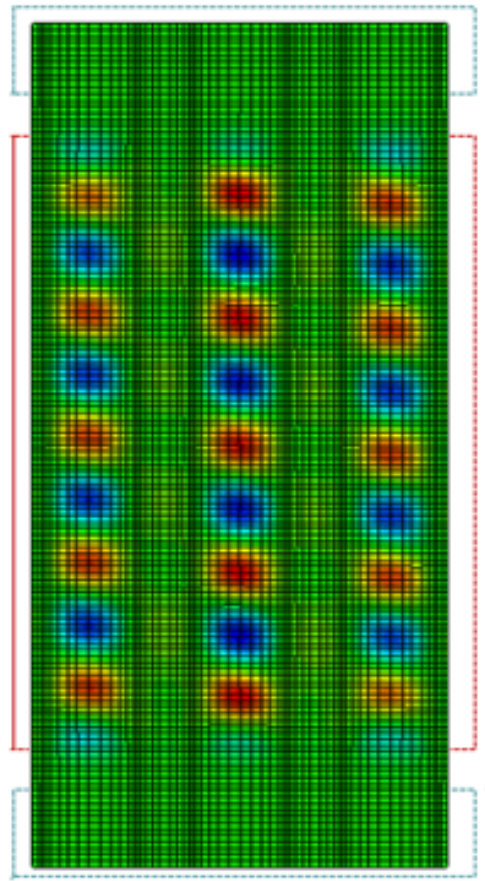

(a) Solid-Noodle Model

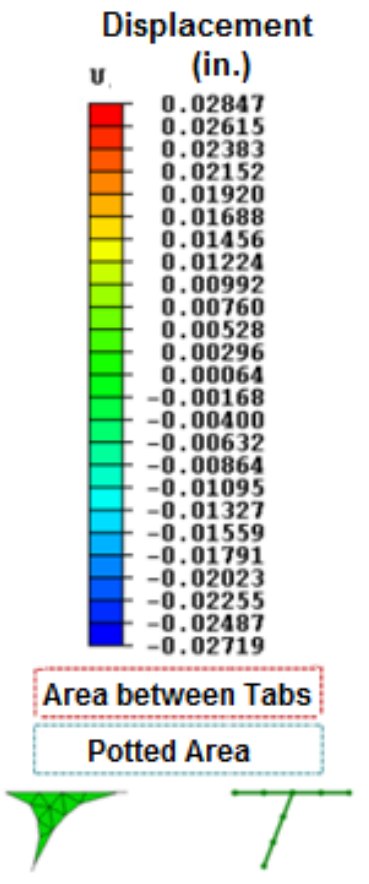

(b) Shell-Noodle Model

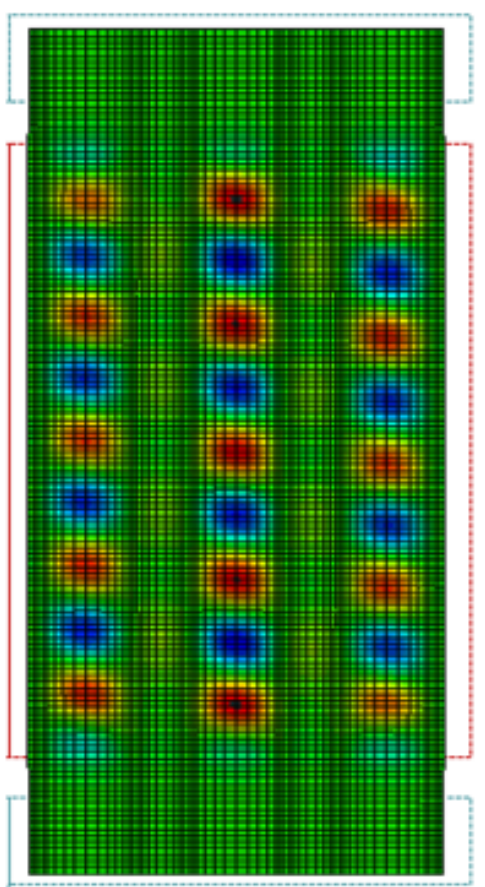

Figure 7. Predicted out-of-plane displacements at 53,100-lb applied compressive load from nonlinear-static analysis on front face of both flat-panel solid-noodle and shell-noodle models. Positive displacements are outward. The black dots on the right image are areas where the displacement resulted slightly higher than the maximum in the scale. 


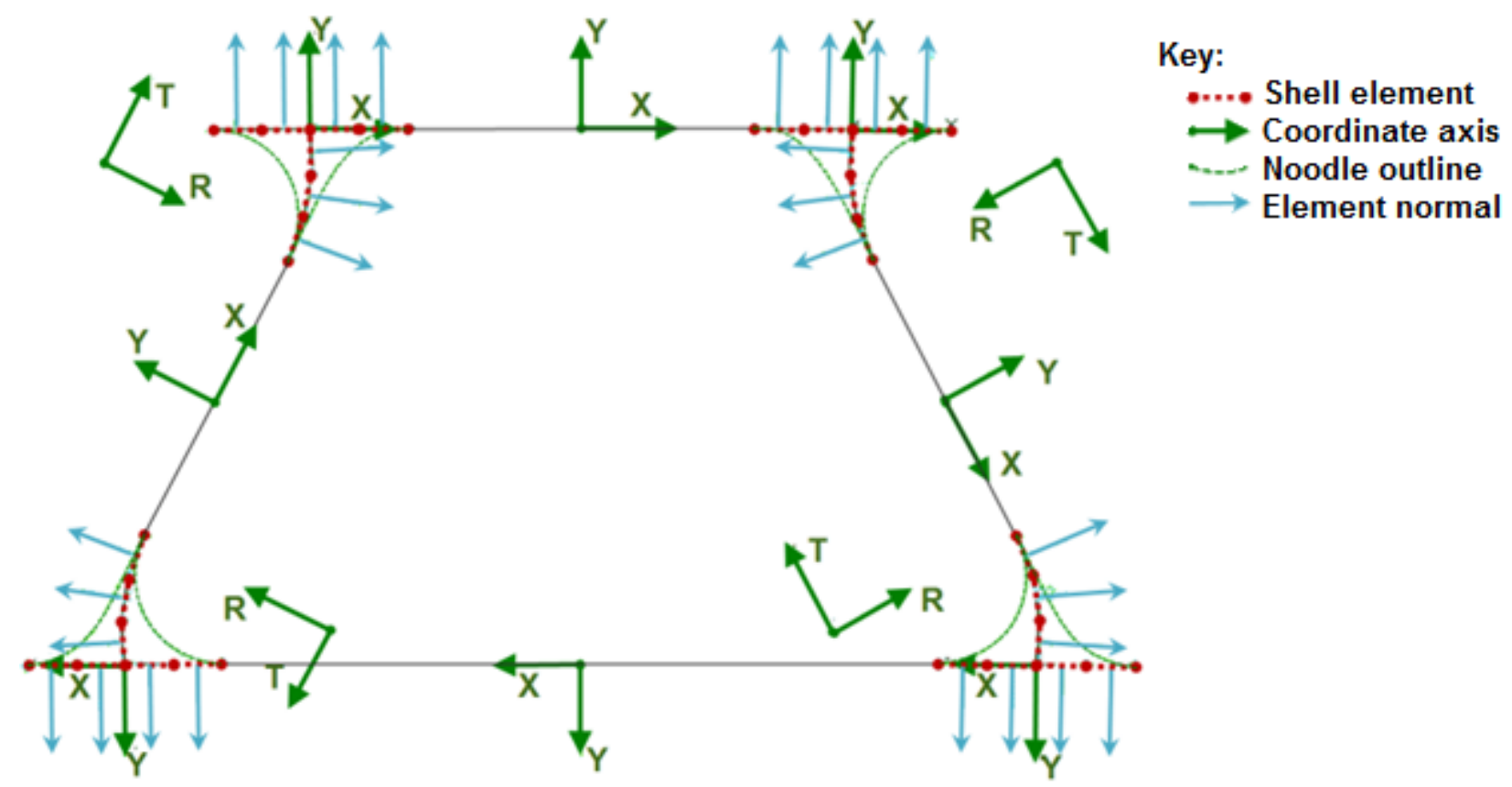

Figure 8. Curved-panel shell-noodle elements within the outline of the original solid-noodle cross sections showing the various (cylindrical and rectangular) coordinate systems used in defining element thickness and offset properties about one of the panel flutes.

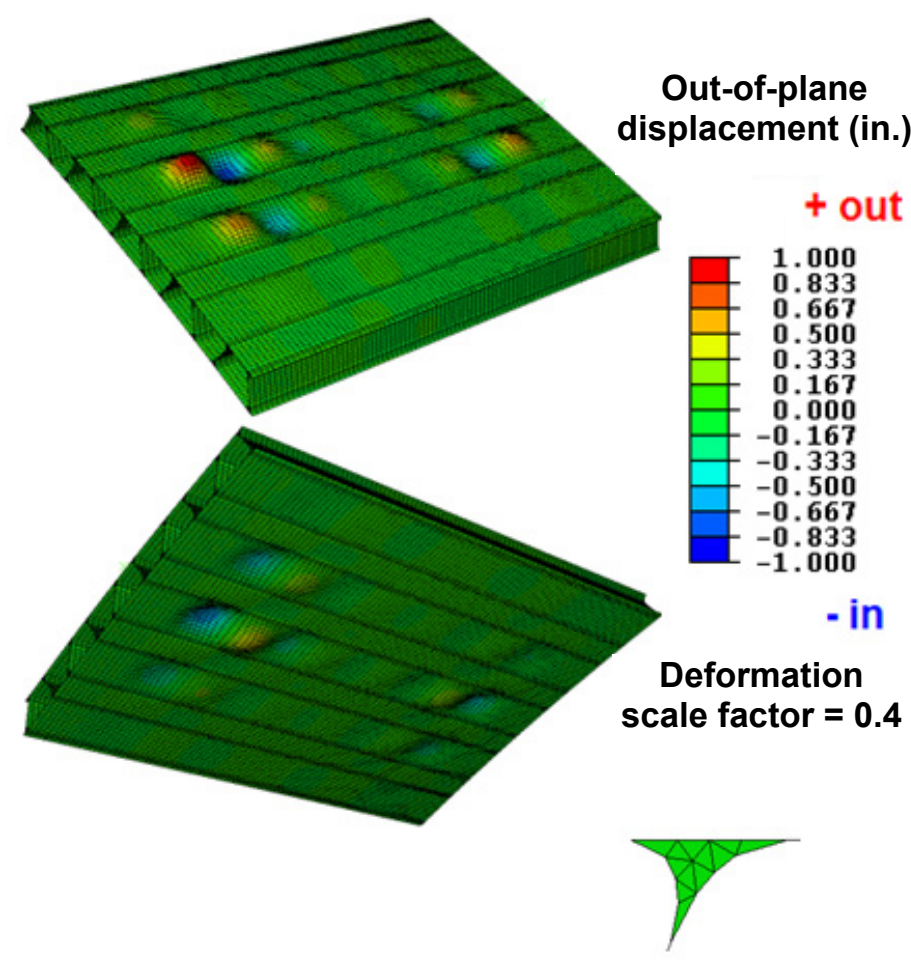

Mode 1: Eigenvalue $=6.5742$

(a) Solid-noodle model

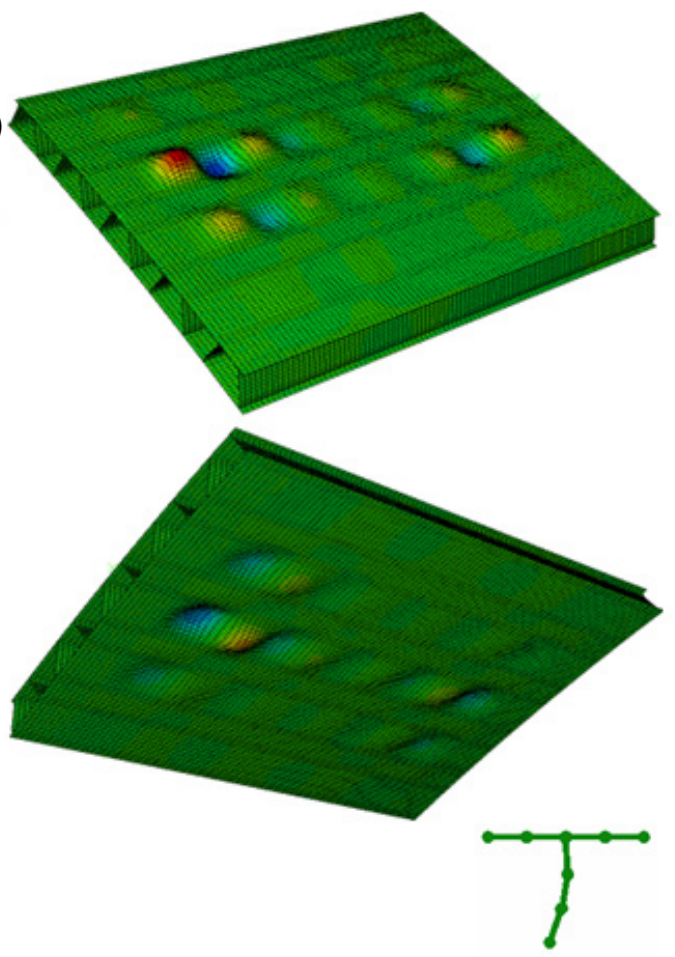

Mode 1: Eigenvalue $=6.5680$

(b) Shell-noodle model

Figure 9. First bifurcation-buckling mode of curved-coupon models under compression loading. 


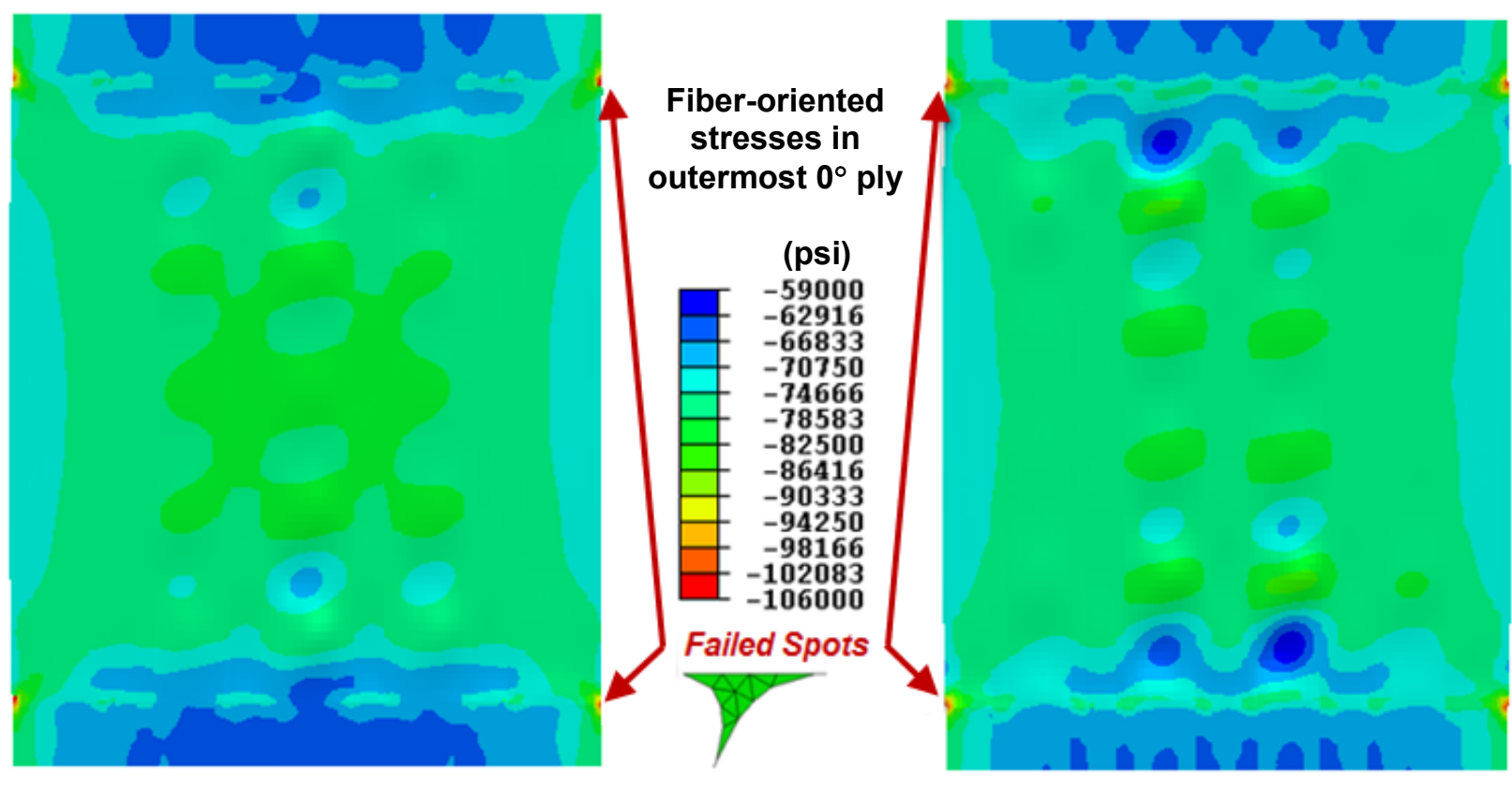

\section{Deformation scale factor $=10$}

(a) Solid-noodle model, IML view

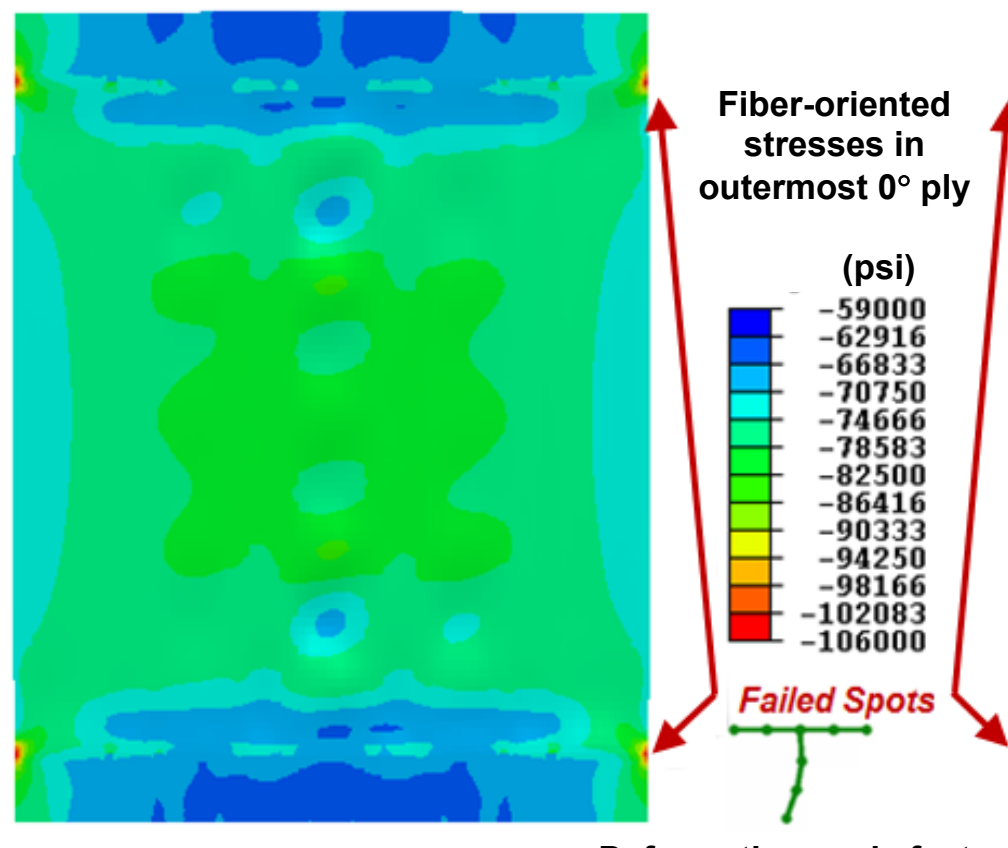

Deformation scale factor $=10$ (b) Solid-noodle model, OML view

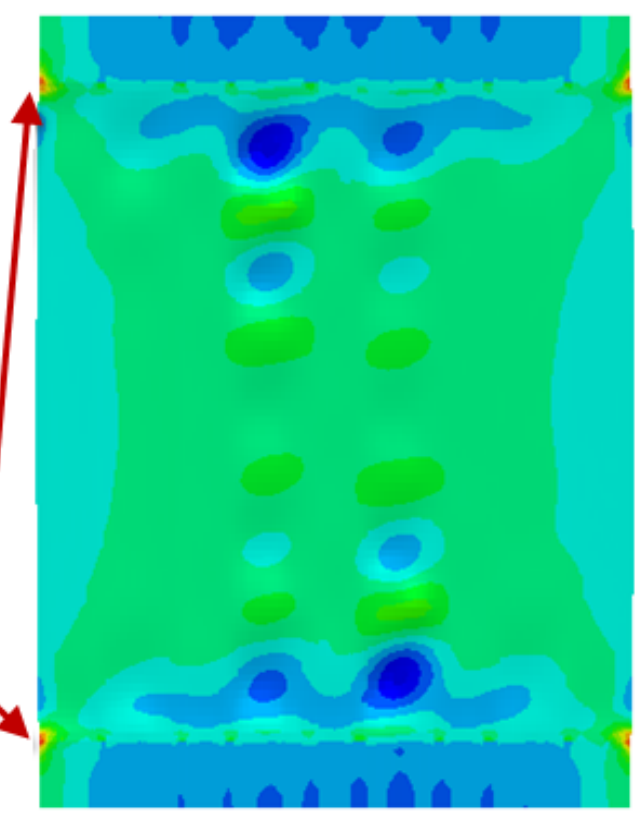

(d) Shell-noodle model, OML view

Figure 10. Fiber-oriented (axial) stresses on the top of the outermost $0^{\circ}$ facesheet ply from nonlinear-static analysis of the curved-coupon models under axial compression at failure load of $39,300 \mathrm{lb}$ for the solid-noodle model and 39,700 $\mathrm{lb}$ for the shell noodle model. 


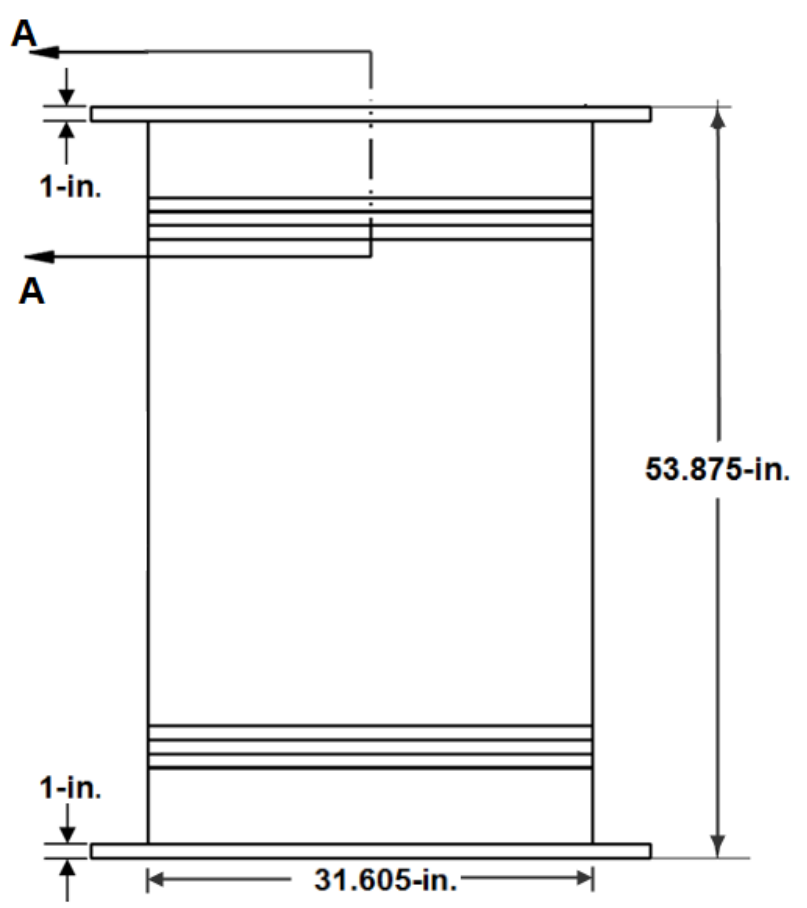

(a) Curved-Panel Dimensions

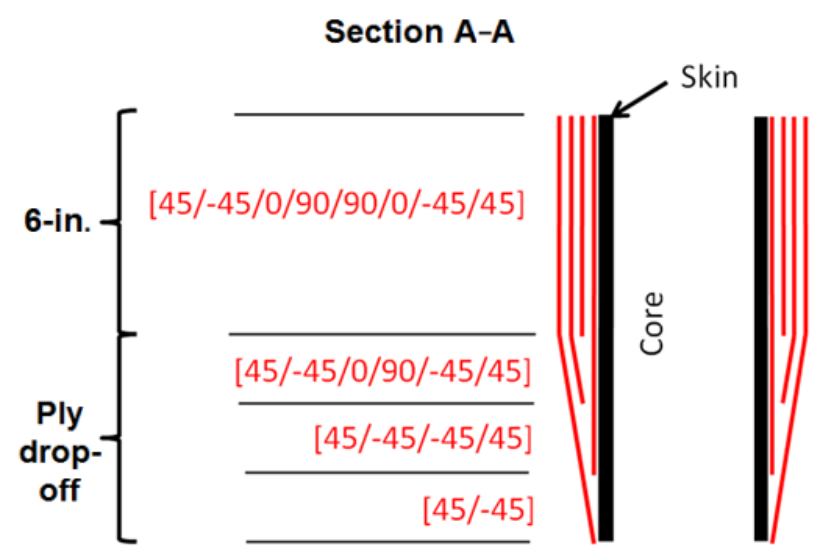

Ply drop-off: 3-in total on 1-in increments. (each red line is a 2-ply set.)

(b) Padup lengths and stacking sequence

Figure 11. The curved panel dimensions and padup arrangement. 


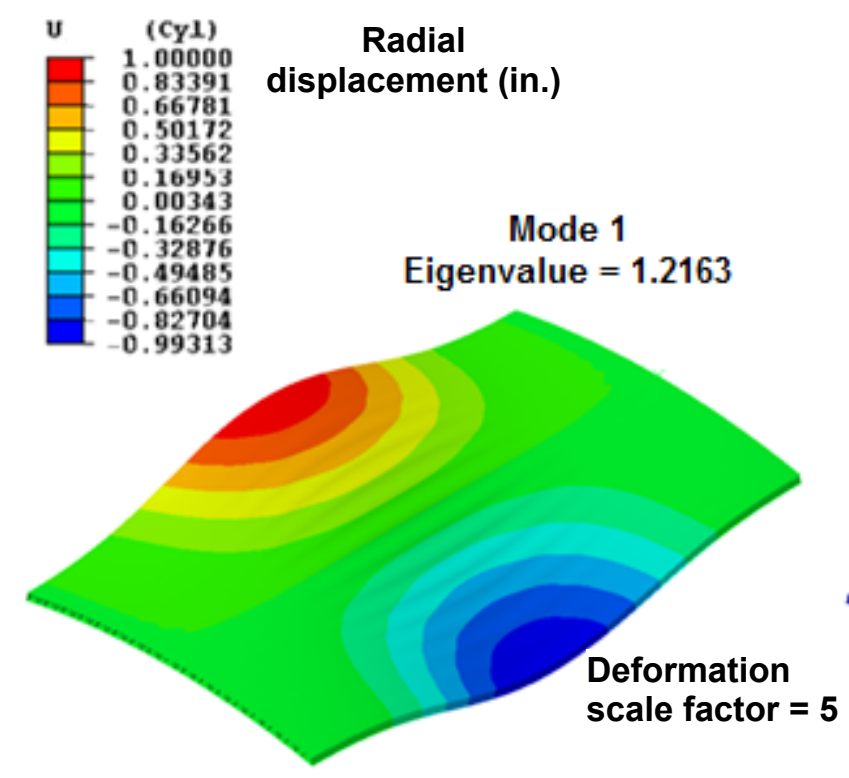

(a) Mode 1

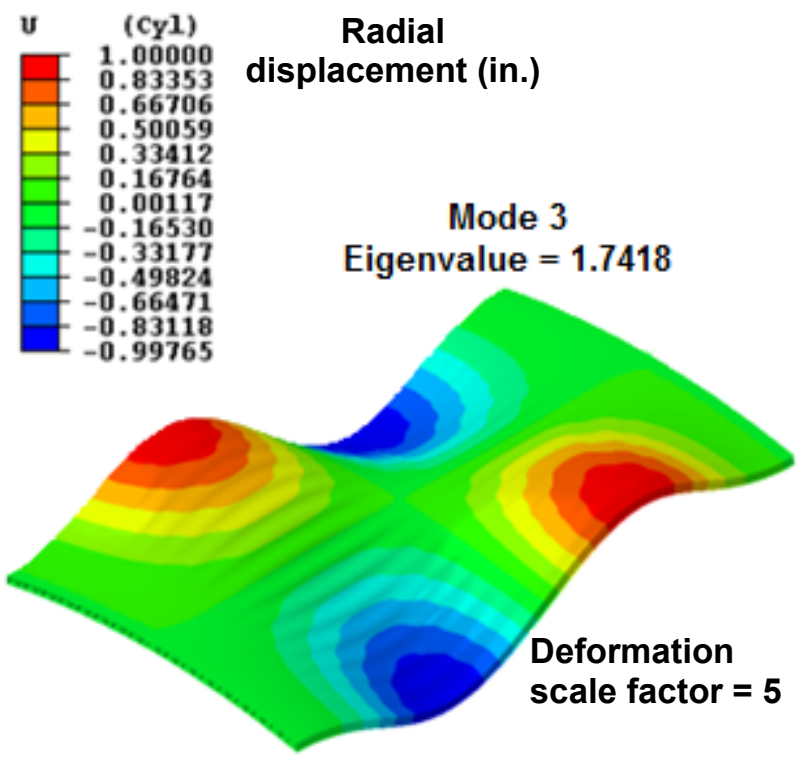

(c) Mode 3

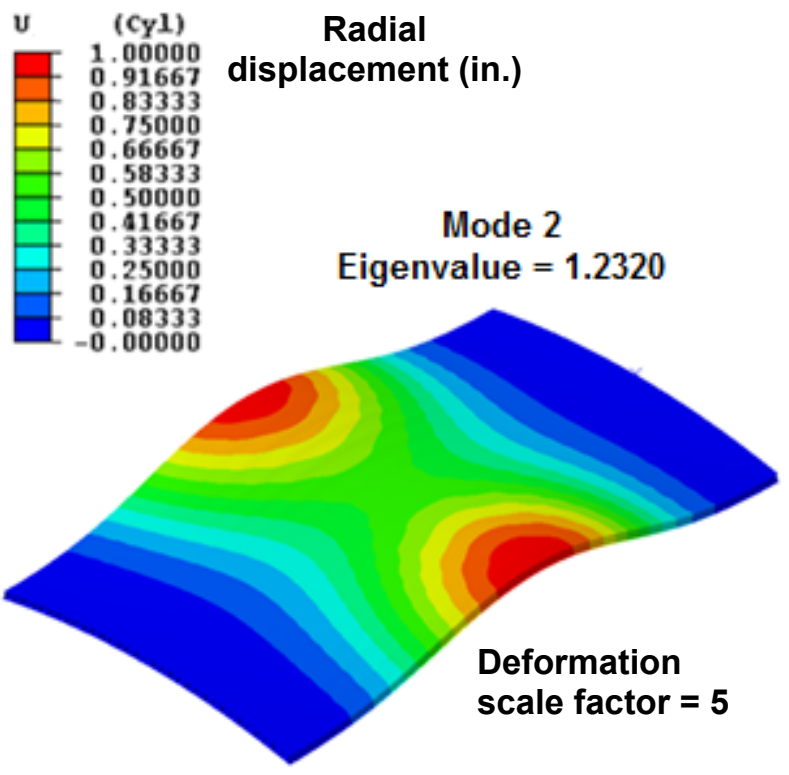

(b) Mode 2

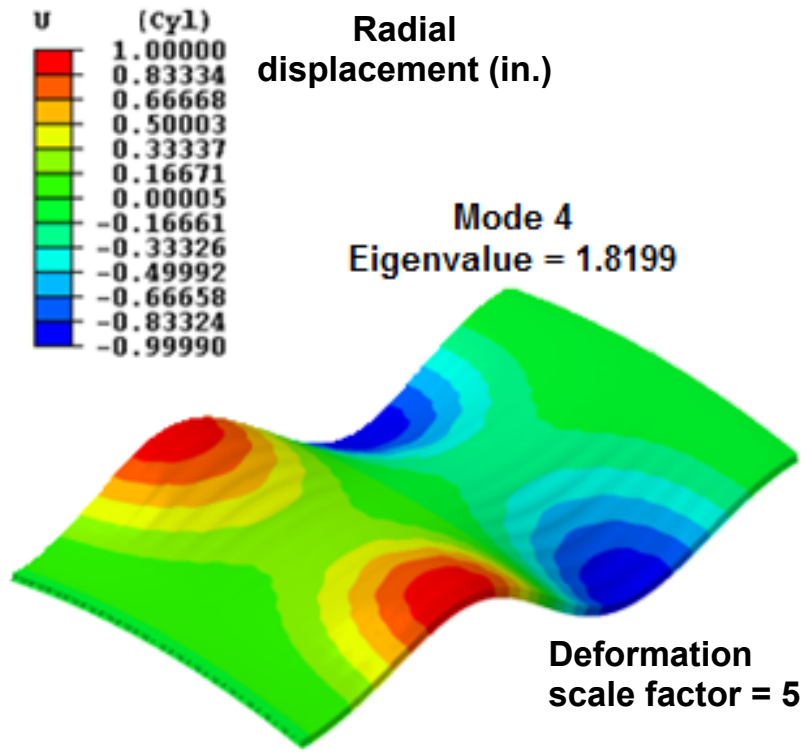

(d) Mode 4

Figure 12. First four bifurcation-buckling modes of the curved panel under axial compression with potted ends and free longitudinal edges. 

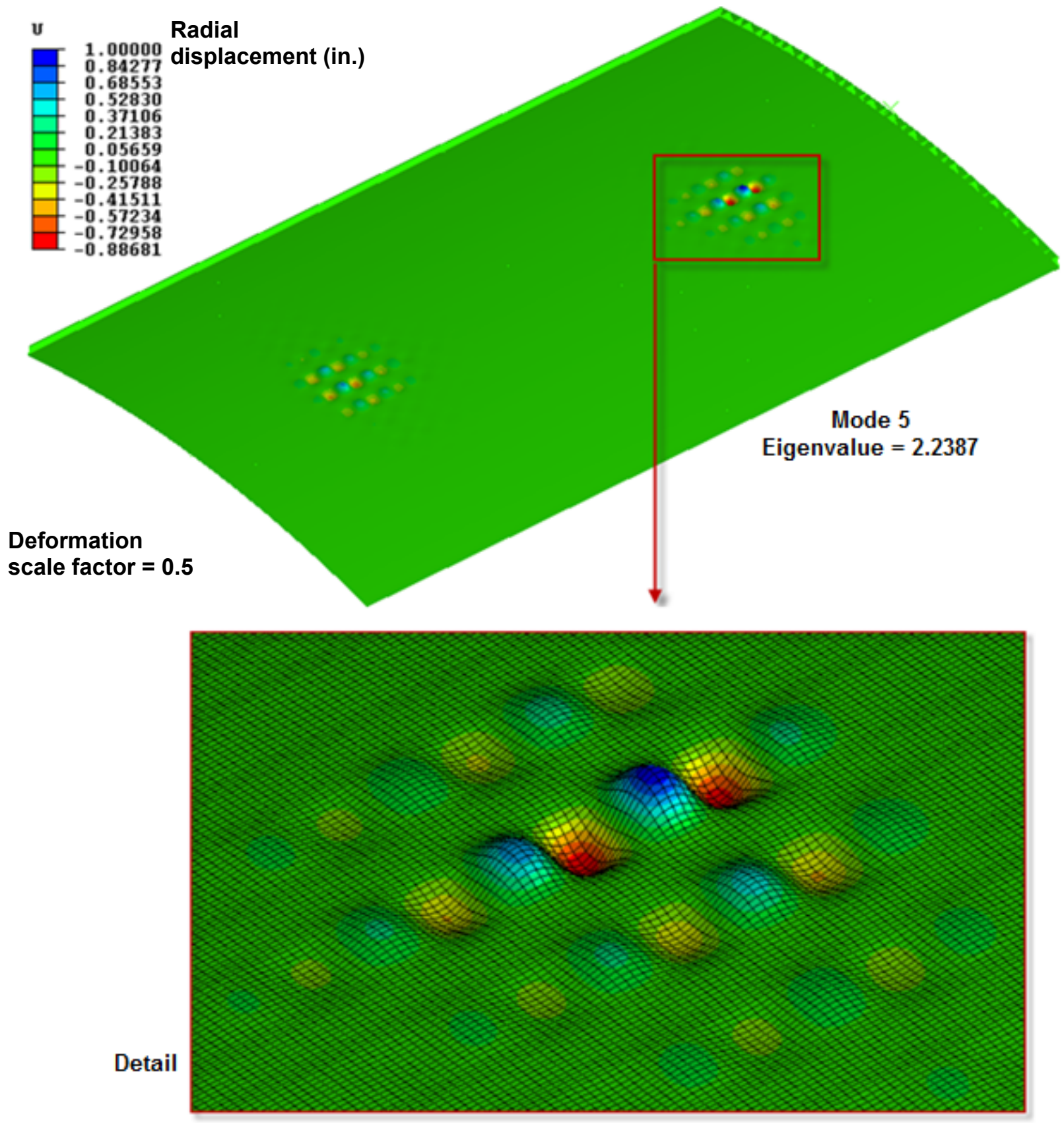

Figure 13. Fifth bifurcation-buckling mode of free-edge and potted, global curved-panel model under axial compression. 


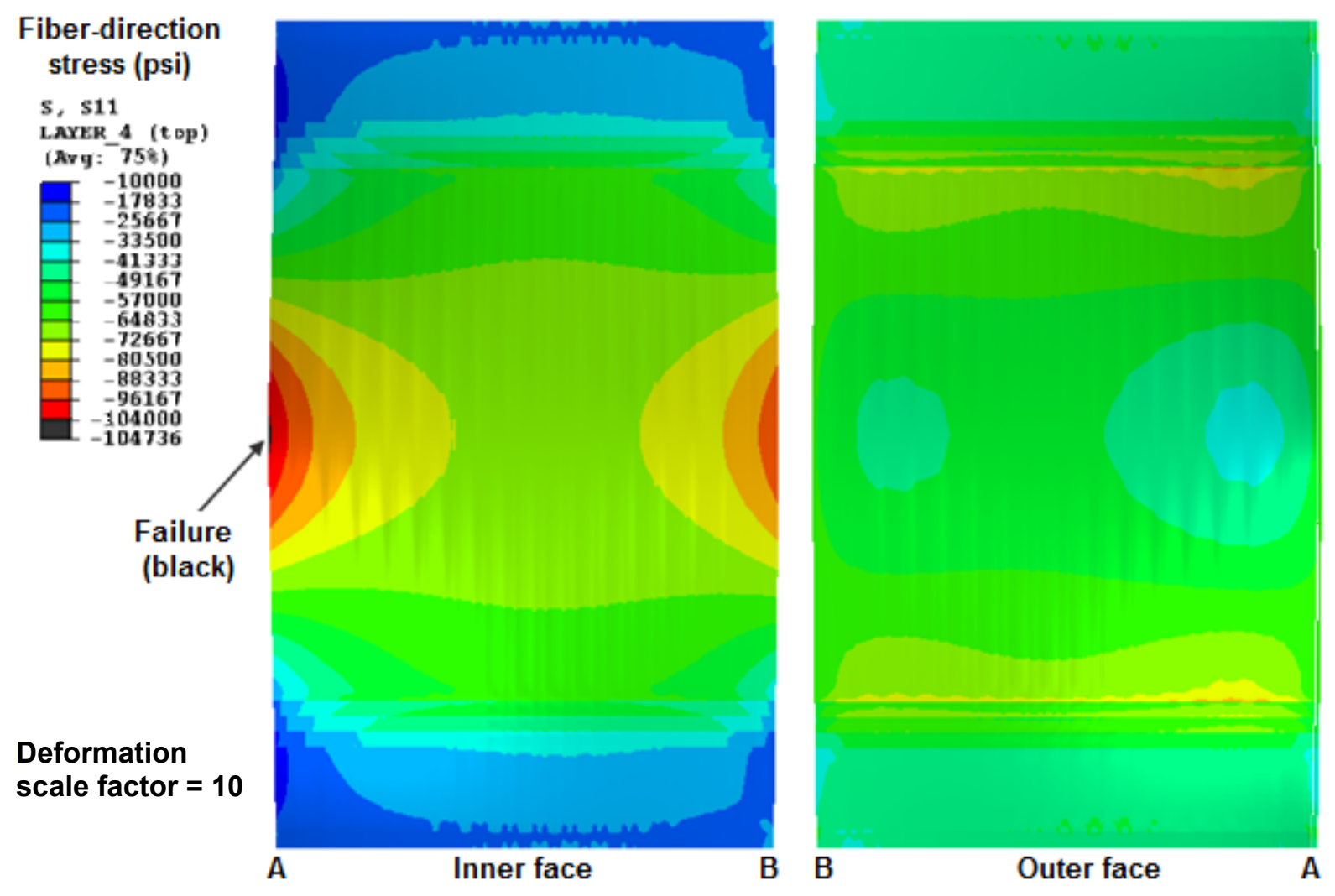

Figure 14. Fiber-oriented stresses on the inner- and outer face top of $0^{\circ}$ ply from nonlinear-static analysis of the curved panel using the shell-noodle sections under axial-compressive loading of $81,000 \mathrm{lb}$. 


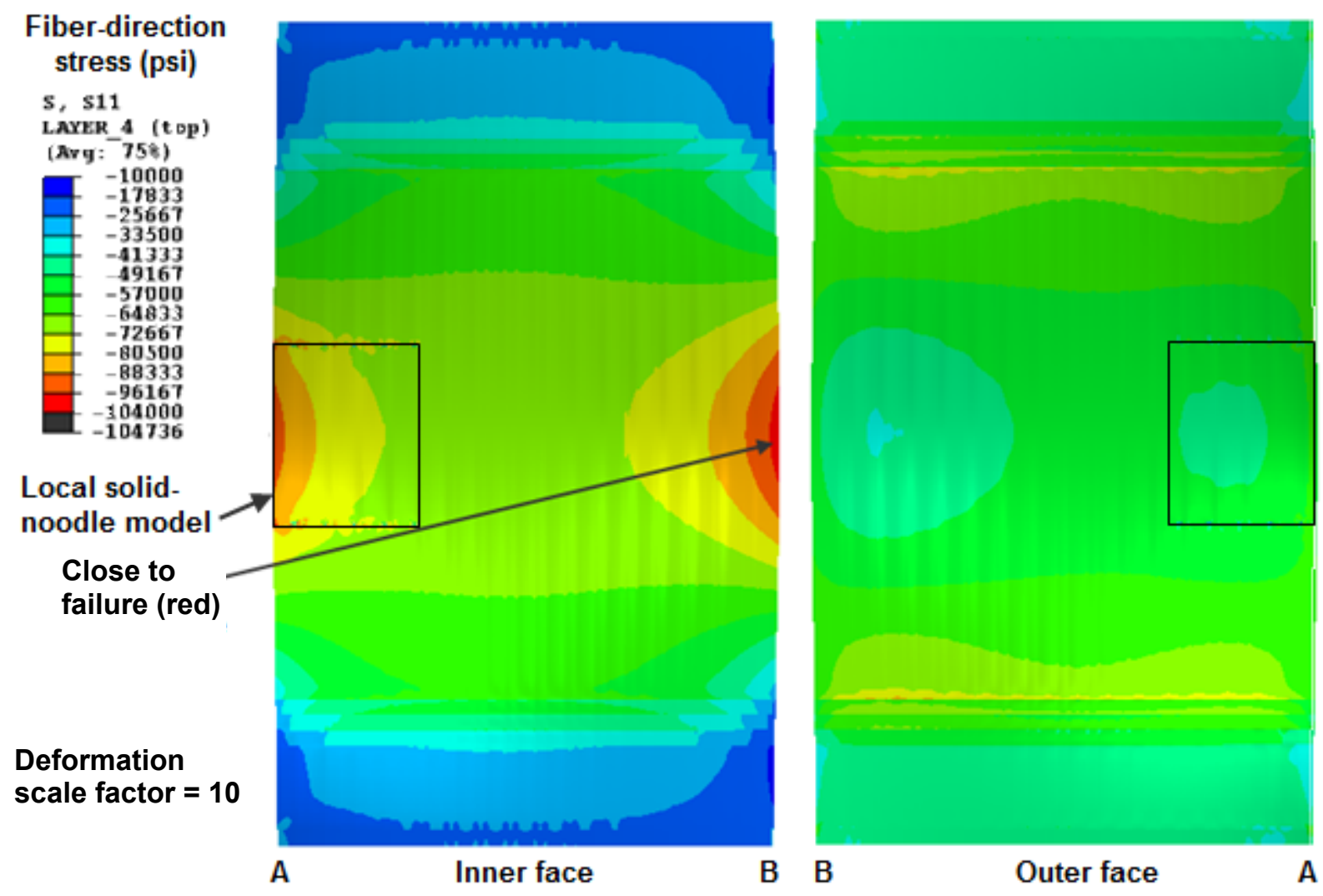

Figure 15. Axial stress in free-edge curved-panel global-local model under axial compression showing continuity of stress between shell-and-solid-noodle sections and the effects of the MPC-driven attachment. 


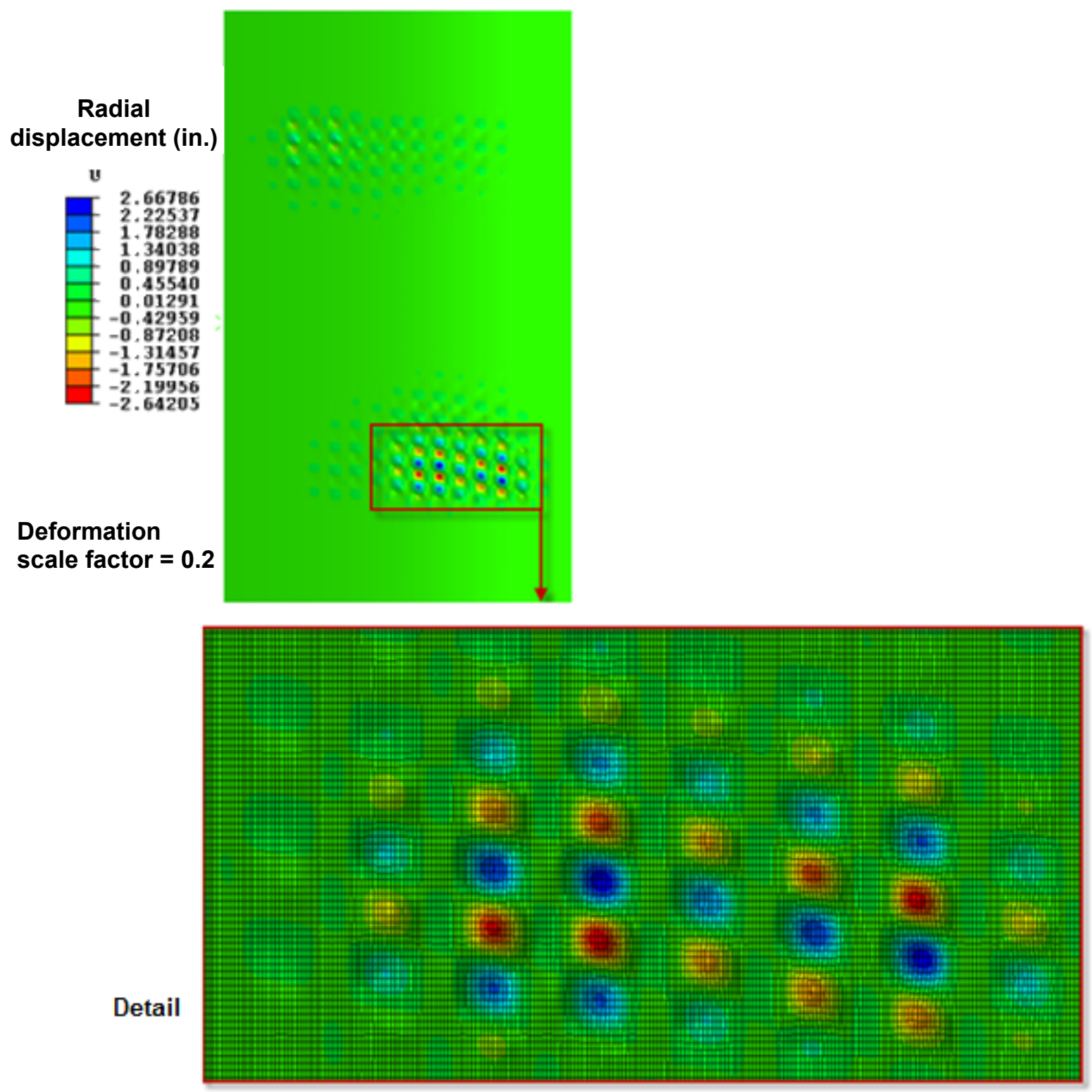

Figure 16. Superposition of the closely packed first eight bifurcation-buckling modes of the curved panel under axial compression with potted ends and potted longitudinal edges. 